\title{
Impact of Parking Maneuvers on the Capacity of the Inlets of Intersections with Traffic Lights for Road Traffic Conditions in Poland
}

\author{
Agata Kurek (D) and Elżbieta Macioszek *(D)
}

check for updates

Citation: Kurek, A.; Macioszek, E. Impact of Parking Maneuvers on the Capacity of the Inlets of Intersections with Traffic Lights for Road Traffic Conditions in Poland. Sustainability 2022, 14, 432. https://doi.org/ $10.3390 /$ su14010432

Academic Editor: Matjaž Šraml

Received: 6 December 2021

Accepted: 29 December 2021

Published: 31 December 2021

Publisher's Note: MDPI stays neutral with regard to jurisdictional claims in published maps and institutional affiliations.

Copyright: (c) 2021 by the authors. Licensee MDPI, Basel, Switzerland. This article is an open access article distributed under the terms and conditions of the Creative Commons Attribution (CC BY) license (https:// creativecommons.org/licenses/by/ $4.0 /)$.
Department of Transport Systems, Traffic Engineering and Logistics, Faculty of Transport and Aviation Engineering, Silesian University of Technology, Krasińskiego 8 Street, 40-019 Katowice, Poland; agata.kurek@polsl.pl

* Correspondence: elzbieta.macioszek@polsl.pl; Tel.: +48-32-603-41-50

\begin{abstract}
The goal of smart cities and sustainable transport is to ensure the efficient movement of people while minimizing a negative impact on the environment. Many cities around the world conduct a policy aimed at limiting parking spaces; however, the complete elimination of parking spaces in cities currently does not seem possible. Parking vehicles cause disturbances in road traffic by searching for a parking space and performing the parking maneuver. This article analyzes the impact of the parking maneuver on the capacity of the inlets of intersections with traffic lights, and the significance of the time it takes to enter and exit a parking space on road traffic disturbance areas under Polish conditions. The research is carried out in on-street parking, characterized by different positions of the parking space to the road, the different surfaces of parking spaces, and the geometry of the road next to which the parking spaces are located. Differences in the time of entry to and exit from the parking space between the research areas indicate that different characteristics of the parking spaces affect the time of the parking maneuver. Drivers wait for the acceptable distance between vehicles on the road into which the vehicle can exit from the parking space. Drivers exiting from perpendicular parking spaces more often cause traffic disruptions than in the case of parallel parking spaces, due to limited visibility. The occupancy of parking spaces directly next to the analyzed ones also affects the time of entry to and exit from the parking space. However, between the time of entry to or exit from the parking space, and the use of the parking space, there is no relationship. This finding indicates that more factors determine the time of entry to and exit from the parking space. The results presented in the article show the need to conduct further research on the impact of parking maneuvers on the capacity of intersections with traffic lights for road traffic conditions in Poland. The results of the research will allow for the design and construction of an optimal parking infrastructure that will meet the needs of road users, while minimizing the negative impact on road conditions and the natural environment following sustainable development.
\end{abstract}

Keywords: planning in road transport; road traffic engineering; on-street parking; intersection with traffic lights; road transport; sustainable transportation

\section{Introduction}

Different groups of road users, i.e., pedestrians, cyclists, and vehicles, move around built-up areas [1]. An important aspect in the case of mixed road traffic is to ensure that all participants can move efficiently and safely on the roads. In built-up areas, the increase in the number of journeys by car and the lack of space for the expansion of road infrastructure has led to an imbalance between supply and demand [2,3]. Achieving this balance is a challenge, due to the uneven distribution of road traffic in time and space [4]. The traffic conditions on the roads in the city reach saturation level during rush hours, whereas outside of the peak period, and at night, the traffic is much lower [5]. The spatial development of the area influences the destination of the journey, determining the road traffic volume 
in urban areas [6,7]. An optimal point and line infrastructure has been designed and built, which should take into account the share of traffic of all road users which, in turn, contributes to delays in travel in the transport network.

Various types of intersections aim to ensure the safe movement of road users with the least time loss. However, intersections contribute to the reduction in the capacity of particular elements of transport networks. Many research works analyze the impact of various factors determining the capacity of intersections with traffic lights, i.a., the presence of pedestrian crossings at inlets [8,9], tram and bus stops [10,11], parking [12,13], participation in the movement of heavy vehicles [14,15], turning vehicles [16,17], queues of vehicles at the inlets [18], etc. Different factors are taken into account in the guidelines for calculating the capacity of intersections with traffic lights in different countries around the world [19-23].

The Polish method [19] takes into account the influence of heavy vehicles, turning vehicles, and pedestrian crossings at inlets, as well as trams or bus stops. The value of the capacity of the intersection with traffic lights is not corrected by the influence of parking maneuvers at the inlet. Each journey by car begins when the vehicle exits from the parking space, and ends when the vehicle enters the parking space. The values of time of entry to or exit from the parking space can affect the road conditions, depending on the location of the parking space. In urban areas with the greatest number of destinations, disruptions caused by the parking maneuver may have a significant impact on the parameters of road traffic, i.e., the travel time and speed of the road section, and the capacity of the road section. Parking spaces located near the intersection with traffic lights also reduce the capacity of the inlets of such intersections.

Drivers are more likely to choose on-street parking than off-street parking because of the convenience of this parking method [24]. The benefits of on-street parking are also indicated for service and commercial buildings, which are located next to on-street parking spaces [25]. The elimination of on-street parking is not possible. However, it is not just the parking maneuver that has a negative impact on road traffic in urban areas; a driver looking for a vacant parking space also causes traffic disruptions [26,27]. The solution in such cases is the use of systems that guide drivers to vacant parking spaces [28-30]. City authorities are taking action to encourage drivers to use parking outside the congested area of the city. Park and ride is designed to encourage drivers to leave their cars on the outskirts of the city and continue their journey using alternative means of transport [31,32].

Based on the literature review, to the knowledge of the authors of the article, studies on the impact of the parking maneuver on the capacity of the inlets of intersections with traffic lights have not been carried out in Polish conditions. This article aims to estimate the influence of parking maneuvers on the capacity of intersections with traffic lights for road traffic conditions in Poland. This estimation is made by comparing the value of the function, and correcting the capacity of the intersection with traffic lights with the conditions of on-street parking. It has been developed in foreign countries based on data from empirical measurements carried out in Poland. Furthermore, the article examines the importance of the impact of the time of entry to and exit from the parking space on traffic disruptions under Polish conditions.

The article consists of six parts. After the introduction, in the second section, the literature review of the impact of parking on traffic conditions is presented. Additionally, models of the impact of on-street parking on the capacity of intersections with traffic lights are characterized. The third part presents materials and methods. The next chapter presents the results of descriptive statistics on the time of entry to and exit from the parking space in different positions of the parking space to the road. The fourth part also contains an analysis of the importance of the impact of the time of entry to and exit from the parking space on road traffic disturbances under Polish conditions, as well as a comparison of the models presented in the literature for the values obtained from measurements carried out in Poland. The article ends with a discussion and conclusions. 


\section{Review of the Scientific Literature}

\subsection{Impact of Parking on Road Traffic Conditions}

The literature on the subject includes works devoted to various aspects of parking [33-35]. A significant part of these works is the study of the impact of parking on road conditions. These works most often include research of the travel time, travel speed, and capacity of the road section with on-street parking, as well as the required time of entry to and exit from the parking space.

In the first group of works related to the analysis of the impact of on-street parking on the travel time of a road section, is the article [36]. The authors, A.I. Portilla et al., present the model of vehicle entry to and exit from the parking space as a Poisson process (queue model). The model of the travel time of the road section with on-street parking depends on such features as the length of the road section, the number of parking maneuvers, the average speed of the road section without disturbances, and the average speed of the road section with disturbances. J. Gao and K. Ozbay [37] propose the same model with the fitted corrective function. This function takes into account the ratio of the real values to the values obtained from the model. The work of H. Guo et al. [38] presents a duration risk model to analyze the impact of on-street parking on travel time. The authors took into account features such as the number of conflicts between vehicles passing the section with vehicles entering or exiting the parking spaces, the number of parking maneuvers, the use of parking spaces, and traffic flow.

The works related to the study of the impact of on-street parking on the speed of the road section include, i.a., the work of Z. Mei and J. Chen [39], which presents a set of heuristic speed functions for one-way and two-way roads. These functions depend on features such as traffic volume, road capacity, speed in free traffic, parking space width, lane width, positions of the parking space to the road, the number of parking maneuvers, and the time of entry to and exit from the parking space. Work S. Sa et al. [40] present a speed model on the road section with on-street parking, based on linear regression analysis. The conducted research shows that the speed of a road section with on-street parking is influenced by features such as the number of parking maneuvers, the time of entry to and exit from the parking space, the number of parked vehicles on the sides of the road, and the traffic volume of various categories of vehicles. The work of M. Patkar and A. Dhamaniya [41] presents speed models which concluded that on-street parking resulted in a reduction in traffic capacity. These models depend on characteristics such as the traffic volume of various vehicle categories, the speed of various vehicle categories, and the number of parking maneuvers. The study also found the impact of parking maneuver on the reduction in road section capacity. The constructed function that reduces the capacity of the road section depends on the number of parking maneuvers.

In the case of the impact of the on-street parking on the capacity of the road section, the authors Y. Cao et al. [42] present a model that corresponds to the conditions when vehicles are parked in a lane, which contributes to the reduction in lane efficiency. The results from the research indicate that if on a two-lane road, one of the lanes is occupied by parked cars, the vehicles may continue to move in two columns. However, the effective width of the lanes decreases. The constructed function depends on features such as road width in one direction, and the width of the lane occupied by parked vehicles. The work of Y. He and J. Li [43] presents a model of the influence of parking maneuvers on the capacity of a road section in two cases. The first case corresponds to the situation that, in front of the vehicle, another car enters or exits a parking space and the driver has to stop and wait until the parked vehicle has finished its maneuver. The second case corresponds to the situation when, in front of the vehicle, another car enters or exits a parking space, forcing the driver to reduce the vehicle speed and move at a reduced speed behind the vehicle entering or exiting the parking space. This model is used when one or two vehicles enter or exit a parking space. The constructed function depends on characteristics such as the time and distance to the place where the parking maneuver is performed, and the average acceleration and deceleration value of the vehicle. 
The work of T. Algburi and H. Özen [44] presents research on the time required to enter or exit a parallel parking space when a vehicle is performing a maneuver: between two parked vehicles, on the side, back, or front of a parked vehicle. S. Yousif [45] presents the results of research on the time of entry to and exit from the parallel and perpendicular parking space. The research results show that a vehicle entering a parking space causes greater traffic disturbances than a vehicle exiting a parking space. Drivers entering a parking space force the traffic flow to reduce speed, stop, or change lanes; when exiting a parking space, they wait for the acceptable distance between vehicles on the road into which the vehicle can exit from the parking space (similar to the gap acceptance theory). In another work, S. Yousif and S.Y. Purnawan [46] proved that exit time from the parking space and join to the traffic takes longer than the entry time to the parking space. The results of the research indicate that there are statistically significant differences between the exit from the parallel parking space and the positions of the parking space to the road. The vehicle entry to the parking space requires less time from the driver and there are no such large differences between the positions of the parking space to the road, as in the case of the exit from the parking space. The study also indicates that the time of entry to the parking space is influenced by such features as positions of the parking space to the road, the direction of travel (i.e., one-way or two-way traffic), the presence of other parked vehicles, the driver's preferences (i.e., reversing or not reversing during entry to or exit from the parking space, especially in the case of the angle parking) and traffic volume. The same author, S. Yousif [47], presents the results of research on the acceptable distance between vehicles moving on the road, into which a vehicle can exit from a parking space. The results show that the mean acceptable distance between vehicles moving on the road into which the vehicle can exit from perpendicular or angle parking spaces is greater than for parallel parking spaces.

\subsection{Models of the Capacity of Intersections with Traffic Lights Taking into Account the Occurrence of a Parking Maneuver at the Inlets}

Table 1 presents selected models to calculate the capacity of intersections with traffic lights. In each of the presented models, the base saturation flow is corrected by the influence of various factors. The influence of the parking maneuver on the capacity value of intersections with traffic lights is taken into account in the models from the USA, Canada, Indonesia, and Australia.

The model of the impact of parking on the capacity at the intersection with traffic lights presented in the Canadian guidelines is a model adopted from HCM 2010, for the case of one lane at the inlet $(N=1)$. However, the assumptions about the possibility of using both models differ. In the case of HCM 2010, the model can be used for on-street parking located up to $80 \mathrm{~m}$ from the stop line at the inlet to the intersection with traffic lights. The model, which is presented in Canadian guidelines, is applicable for on-street parking located up to $50 \mathrm{~m}$ from the stop line at the inlet to the intersection with traffic lights. Indonesian guidelines assume that on-street parking impacts the capacity of the inlet of the intersection with traffic lights when it is less than $75 \mathrm{~m}$ from the stop line. The distance between the on-street parking and the stop line at the inlet to the intersection with traffic lights is not specified in the model for Australian conditions [13].

For the models presented in Table 1, the correction functions are determined for the theoretical values (Figure 1). The value of the function in HCM 2010 decreases along with an increase in the number of parking maneuvers, which also reduces the capacity of the intersection with traffic lights. The increase in the number of lanes at the inlet means that with the increase in the number of parking maneuvers, the function does not decrease as rapidly as in the case of one lane at the inlet. As previously explained, the model presented in the Canadian guidelines has the same form as the model presented in HCM 2010 for one lane at the inlet. 
Table 1. Selected models for calculating the capacity of intersections with traffic lights, taking into account the occurrence of a parking maneuver at the inlets.

\begin{tabular}{|c|c|c|c|c|}
\hline $\begin{array}{l}\text { Guidelines/ } \\
\text { Paper }\end{array}$ & $\begin{array}{l}\text { Model of the Capacity of the } \\
\text { Intersection with Traffic Lights }\end{array}$ & The Variables in the Formula for Capacity & $\begin{array}{l}\text { Model of the Impact of Parking } \\
\text { Maneuver on the Value of the Capacity } \\
\text { of the Inlet of Intersection with Traffic } \\
\text { Lights (Correcting Function) }\end{array}$ & $\begin{array}{l}\text { The Variables in the Formula for the } \\
\text { Impact of Parking on the Value of the } \\
\text { Capacity of the Inlet of } \\
\text { Intersection with Traffic Lights }\end{array}$ \\
\hline $\begin{array}{l}\text { Highway } \\
\text { Capacity } \\
\text { Manual } \\
\text { [48] }\end{array}$ & $\begin{array}{c}S=S_{\mathrm{o}} \cdot f_{\mathrm{w}} \cdot f_{\mathrm{HF}} \cdot f_{\mathrm{g}} \cdot f_{\mathrm{p}} \cdot f_{\mathrm{bb}} \cdot f_{\mathrm{a}} \cdot \\
\quad f_{\mathrm{LU}} \cdot f_{\mathrm{LT}} \cdot f_{\mathrm{RT}} \cdot f_{\mathrm{Lpb}} \cdot f_{\mathrm{Rpb}} \\
{[\mathrm{Pcu} / \mathrm{h} / \text { lane }]}\end{array}$ & $\begin{array}{l}S_{\mathrm{o}} \text {-base saturation flow [pcu/h/lane]; } \\
f_{\mathrm{w}} \text {-adjustment factor for lane width; } \\
f_{\mathrm{HV}} \text {-adjustment factor for heavy vehicles; } \\
f_{\mathrm{g}} \text {-adjustment factor for the gradient; } \\
f_{\mathrm{p}} \text {-adjustment factor for the parking; } \\
f_{\mathrm{bb}} \text {-adjustment factor for the bus stop; } \\
f_{\mathrm{a}} \text {-adjustment factor for area type; } \\
f_{\mathrm{LU}} \text {-adjustment factor for lane utilization; } \\
f_{\mathrm{LT}} \text {-adjustment factor for the left turn; } \\
f_{\mathrm{RT}} \text {-adjustment factor for the right turn; } \\
f_{\mathrm{Lpb}} \text {-pedestrian adjustment factor for the left turn; } \\
f_{\mathrm{Rpb}} \text { - pedestrian-bicycle adjustment factor for the } \\
\text { right turn. }\end{array}$ & $f_{p}=\frac{N-0.1-\frac{18 \cdot N m}{3600}}{N}$ & $\begin{array}{l}N \text {-number of lanes in lane group; } \\
N_{\mathrm{m}}-\text { number of parking maneuvers } \\
\text { [Veh./h]. }\end{array}$ \\
\hline $\begin{array}{l}\text { Canadian } \\
\text { Capacity } \\
\text { Guide for } \\
\text { Signalized } \\
\text { Intersection } \\
\quad \text { [21] }\end{array}$ & $\begin{aligned} S_{\text {adj }}= & S_{\text {basic }} \cdot f\left(f_{\text {adj }}\right) \\
& {[\mathrm{Pcu} / \mathrm{h}] }\end{aligned}$ & $\begin{array}{l}S_{\text {basic }}-\text { base saturation flow }[\mathrm{Pcu} / \mathrm{h}] \\
f\left(f_{\text {adj }}\right) \text { - adjustment functions. }\end{array}$ & $f_{\mathrm{p}}=0.90-0.005 \cdot N_{\mathrm{m}}$ & $\begin{array}{l}N_{\mathrm{m}} \text {-number of parking maneuvers } \\
\text { [Veh./h]. }\end{array}$ \\
\hline $\begin{array}{l}\text { Indonesian Highway } \\
\text { Capacity Manual } \\
\text { [49] }\end{array}$ & $\begin{array}{c}S=S_{\mathrm{o}} \cdot f_{\mathrm{cs}} \cdot f_{\mathrm{sp}} \cdot f_{\mathrm{g}} \cdot f_{\mathrm{p}} \cdot f_{\mathrm{rt}} \cdot f_{\mathrm{lt}} \\
{[\mathrm{Pcu} / \mathrm{hg}]}\end{array}$ & $\begin{array}{l}S_{\mathrm{o}} \text {-base saturation flow [Veh./hg]; } \\
f_{\mathrm{cs}} \text {-adjustment factor for the city size; } \\
f_{\mathrm{sp}} \text {-adjustment factor for the side friction; } \\
f_{\mathrm{g}} \text {-adjustment factor for the gradient; } \\
f_{\mathrm{p}} \text {-adjustment factor for the parking; } \\
f_{\mathrm{rt}} \text {-adjustment factor for the right turn; } \\
f_{\mathrm{lt}} \text {-adjustment factor for the left turn. }\end{array}$ & $f_{p}=\frac{\frac{L_{p}}{3}-\left(W_{A}-2\right) \cdot \frac{\frac{L_{p}}{3}-g}{W_{A}}}{g}$ & $\begin{array}{l}L_{\mathrm{p}} \text {-the distance between stop-line and first } \\
\text { parked vehicle }[\mathrm{m}] \\
W_{\mathrm{A}} \text { - width of the approach }[\mathrm{m}] \\
g \text {-green time in the approach }[\mathrm{s}]\end{array}$ \\
\hline
\end{tabular}


Table 1. Cont.

\begin{tabular}{|c|c|c|c|c|}
\hline $\begin{array}{l}\text { Guidelines/ } \\
\text { Paper }\end{array}$ & $\begin{array}{l}\text { Model of the Capacity of the } \\
\text { Intersection with Traffic Lights }\end{array}$ & The Variables in the Formula for Capacity & $\begin{array}{l}\text { Model of the Impact of Parking } \\
\text { Maneuver on the Value of the Capacity } \\
\text { of the Inlet of Intersection with Traffic } \\
\text { Lights (Correcting Function) }\end{array}$ & $\begin{array}{l}\text { The Variables in the Formula for the } \\
\text { Impact of Parking on the Value of the } \\
\text { Capacity of the Inlet of } \\
\text { Intersection with Traffic Lights }\end{array}$ \\
\hline $\begin{array}{c}\text { S. Wijayaratna } \\
\text { [13] } \\
\text { (Australia) }\end{array}$ & $\begin{array}{c}C=\underset{ }{[\mathrm{Pcu} / \mathrm{hg}]} \\
1800 \cdot f_{\mathrm{W}} \cdot f_{\mathrm{HV}} \cdot f_{\mathrm{p}}\end{array}$ & $\begin{array}{l}\text { 1800—capacity of a traffic lane without } \\
\text { overtaking capabilities; } \\
f_{\mathrm{W}} \text {-adjustment factor for narrow lanes and lateral } \\
\text { clearances; } \\
f_{\mathrm{HV}} \text {-adjustment factor for heavy vehicles; } \\
f_{\mathrm{p}} \text {-adjustment factor for the parking. }\end{array}$ & $f_{p}=3600-N_{p} \cdot N_{t} \cdot \frac{t_{p 1}+k \cdot t_{p o}}{3600}$ & $\begin{array}{l}N_{\mathrm{p}} \text {-number of parking spaces }\left(\mathrm{L}_{\mathrm{p}} / 6\right) ; \\
L_{\mathrm{p}}-\text { length of the on-street parking zone [m]; } \\
N_{\mathrm{t}} \text {-rotation indicator [Veh./parking } \\
\text { space/h]; } \\
t_{\mathrm{p} 1} \text {-average entry time to the parking } \\
\text { space [s]; } \\
t_{\mathrm{po}} \text {-average exit time from the parking } \\
\text { space [s]; } \\
k-\text { reduction factor for } t_{\mathrm{po}}[-] .\end{array}$ \\
\hline $\begin{array}{l}\text { The method } \\
\text { of calculating } \\
\text { the capacity } \\
\text { of } \\
\text { intersections with } \\
\text { traffic lights [19] } \\
\text { (Poland) }\end{array}$ & $\begin{array}{c}S_{j}=S_{j}^{W} \cdot f_{a} \cdot f_{t}[\mathrm{Pcu} / \mathrm{hg}] \\
S_{r}=S_{0} \cdot f_{p} \cdot \frac{1}{1+u_{r}}[\mathrm{Pcu} / \mathrm{hg}]\end{array}$ & $\begin{array}{l}\left.S_{j} \text {-saturation flow of lane } j \text { [Veh. } / \mathrm{hg}\right] \\
S_{j}^{w} \text { - base saturation flow for lane } \mathrm{j} \text { taking into } \\
\text { account geometric factors, the collision of relations, } \\
\text { and the traffic generic structure [Veh./hg]; } \\
f_{\mathrm{a}} \text {-adjustment factor for the bus stop; } \\
f_{\mathrm{t}} \text {-adjustment factor for the tram stop; } \\
S_{\mathrm{r}} \text { - saturation flow for collision turning vehicles } \\
\text { with pedestrian [Veh./hg]; } \\
S_{\mathrm{o}} \text { - base saturation flow [Veh./h]; } \\
f_{\mathrm{a}} \text {-adjustment factor for pedestrian traffic; } \\
u_{\mathrm{c}} \text { - participation in the traffic of heavy vehicles. }\end{array}$ & - & \\
\hline
\end{tabular}


(a)

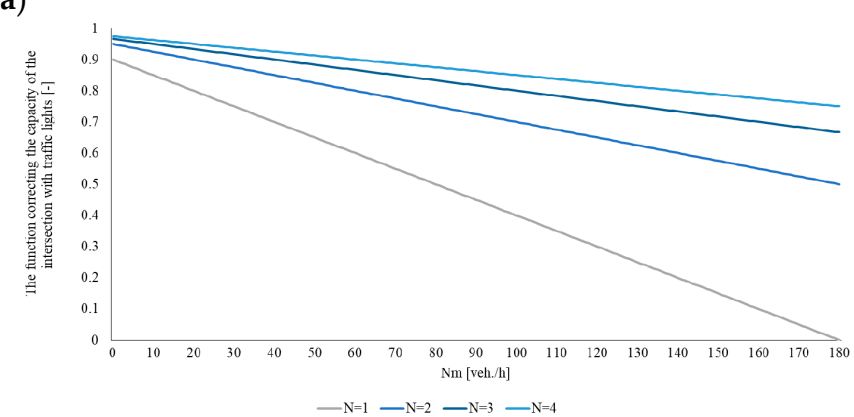

(c)

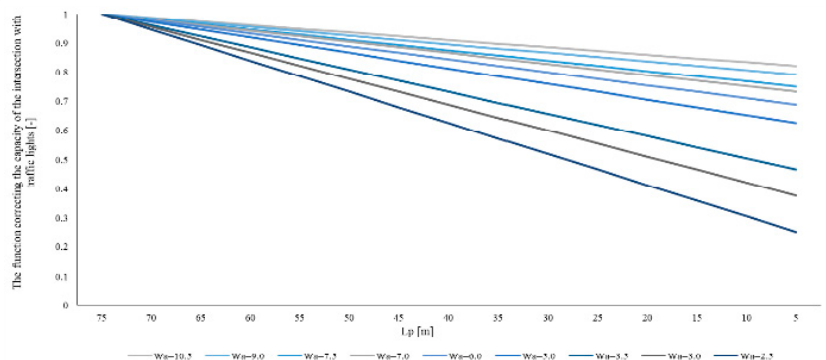

(e)

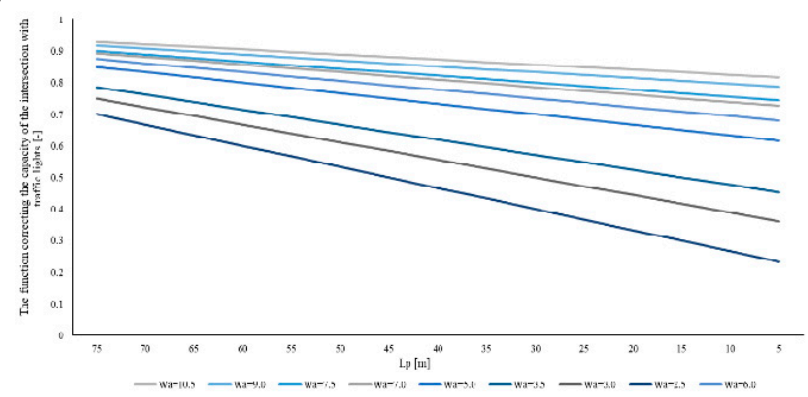

(b)

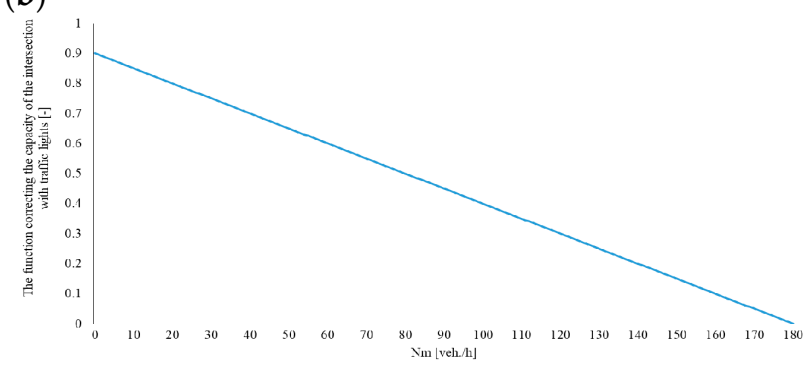

(d)

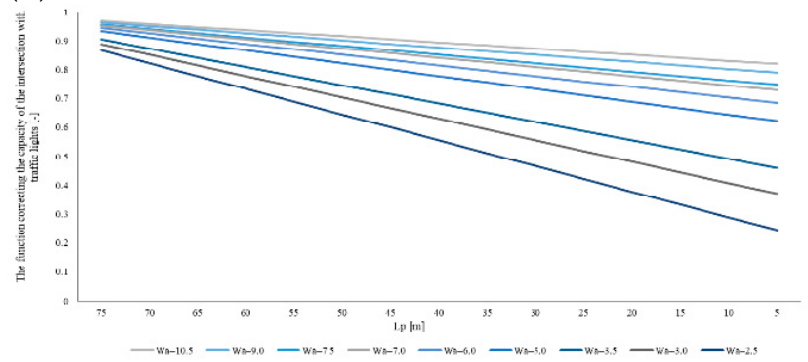

(f)

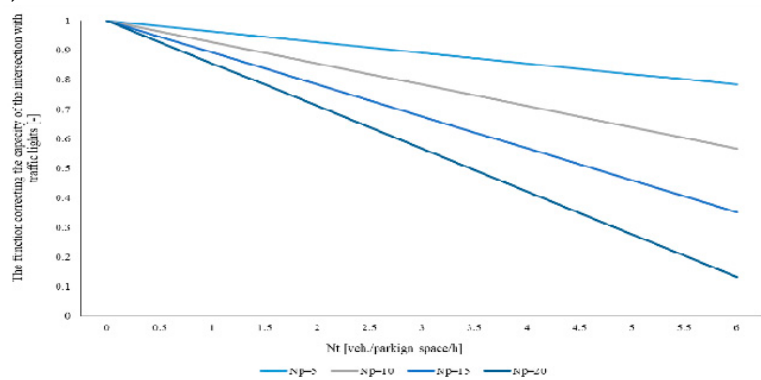

Figure 1. The function correcting the capacity of the inlet of intersections with traffic lights due to the presence of on-street parking, according to: (a) HCM 2010; (b) Canadian Capacity Guide for Signalized Intersection; (c) Indonesian Highway Capacity Manual for g = $25 \mathrm{~s}$; (d) Indonesian Highway Capacity Manual for $\mathrm{g}=30 \mathrm{~s}$; (e) Indonesian Highway Capacity Manual for g = $40 \mathrm{~s}$; (f) S. Wijayaratna (Australia).

In the case of the Indonesian model, three functions are presented for the duration of the green signal of $25 \mathrm{~s}, 30 \mathrm{~s}$, and $40 \mathrm{~s}$. For the length of the green signal equal to $40 \mathrm{~s}$, for the maximum distance of the on-street parking from the stop line, the function values for the particular lane widths differ to a greater extent than for the shorter duration of the green signal. A longer green signal causes a greater reduction in the capacity of the intersections with traffic lights than a shorter green signal. In the case of entry to or exit from the parking space during the red signal, the driver behind this vehicle will not lose time, if the green signal is not displayed until the vehicle reaches the end of the queue.

In [13], the values of the average time taken to enter or exit a parking space are given. However, the value of the function that corrects the time of exit from the parking space is equal to zero, because vehicles exiting the parking space do not cause disturbances in road traffic. An increase in the rotation indicator causes a decrease in the value of the correcting function, which translates into a reduction in the capacity of the intersection with traffic lights. The increase in the available number of parking spaces means that, along with the increasing rotation indicator at parking spaces, the correcting function approaches zero faster than in the case of a smaller number of parking spaces.

Functions for HCM, the Canadian Capacity Guide for Signalized Intersection, and the Indonesian Highway Capacity Manual, for $\mathrm{g}=30 \mathrm{~s}$ and $\mathrm{g}=40 \mathrm{~s}$, never equal 1.0. This means that if the parking maneuver does not occur in the analyzed period, the presence of 
the parking contributes to a reduction in the capacity of the intersection with traffic lights. This may be due to the so-called search traffic, i.e., traffic caused by drivers searching for a parking space, or unpredictable behavior of drivers of vehicles located at parking spaces, e.g., opening doors, getting out of the car, etc. More lanes and a wider roadway allow overtaking vehicles, and make entering or exiting a parking space easier. This, in turn, contributes to less disruption to road traffic caused by a vehicle entering or exiting parking space than in a case of a one-lane road or a narrower roadway.

\section{Materials and Methods}

In the first stage of the work, an inventory of the on-street parking infrastructure was carried out in selected cities in Poland. The selection of cities for the inventory of parking infrastructure was made by an expert method, based on basic assumptions regarding the motorization indicator and the population density indicator. Selected cities should have a motorization indicator of at least 580 vehicles per 1000 inhabitants and a population density indicator of at least 1500 people per $1 \mathrm{~km}^{2}$. Warsaw, Krakow, Wroclaw, Rzeszow, and Lodz were selected for the research. These cities are the capitals of the provinces in which they are located. A total of 118,862 particular parking spaces were inventoried in 8389 parking zones. Figure 2 shows the structure of the inventoried parking spaces in terms of the positions of the parking space to the road. The largest number of inventoried parking spaces were parallel parking spaces, slightly fewer were perpendicular parking spaces, and the smallest group was angle parking spaces. Therefore, areas with perpendicular and parallel parking spaces were selected for empirical research.

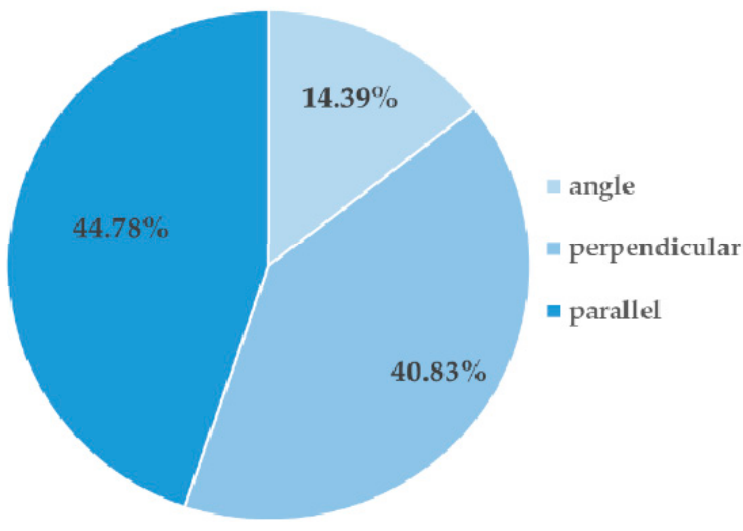

Figure 2. The structure of the inventoried parking spaces in terms of the position of the parking spaces to the road.

Field research was carried out in on-street parking in selected cities in three different locations (hereinafter named, respectively, research area 1 , research area 2 , and research area 3). Table 2 presents the characteristics of the research areas.

Table 2. Characteristic of research areas.

\begin{tabular}{lccc}
\hline \multicolumn{1}{c}{ Characteristic } & Research Area 1 & Research Area 1 & Research Area 1 \\
\hline The positions of the parking & Parallel & Perpendicular & Parallel \\
space to the road & $1 \times 3$ & $1 \times 2$ & $2 \times 1$ \\
Road geometry & 3 & 3.5 & 3.5 \\
Lane width [m] & 8 & 28 & 5 \\
Number of parking spaces & Same as the road, no road & $\begin{array}{c}\text { Slightly elevated to the road } \\
\text { surface, a single parking space } \\
\text { The surface of parking spaces }\end{array}$ & $\begin{array}{c}\text { Slightly elevated to the road } \\
\text { surface, a single parking space } \\
\text { marked with a different color } \\
\end{array}$ \\
& markings separating a single \\
parking space & of paving stones & \begin{tabular}{c} 
of paving stones \\
\hline
\end{tabular}
\end{tabular}


Measurements of features related to the parking maneuver were made with the use of digital cameras. Figure 3 shows the locations of the measuring stations in the three research areas.

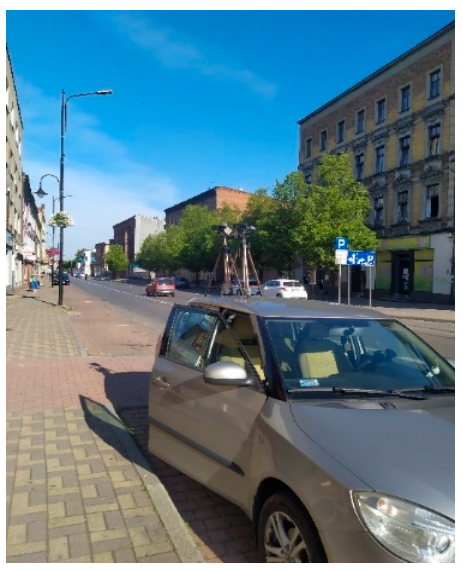

(a)

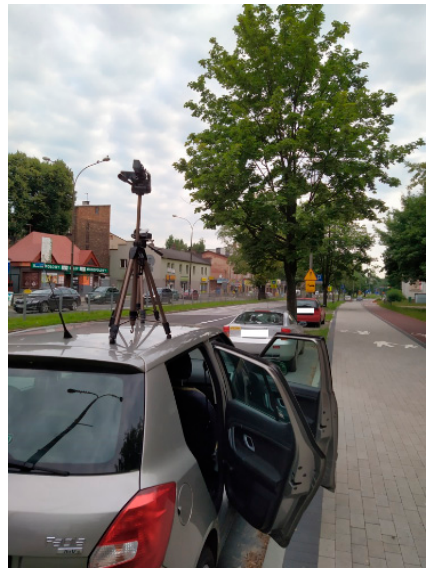

(b)

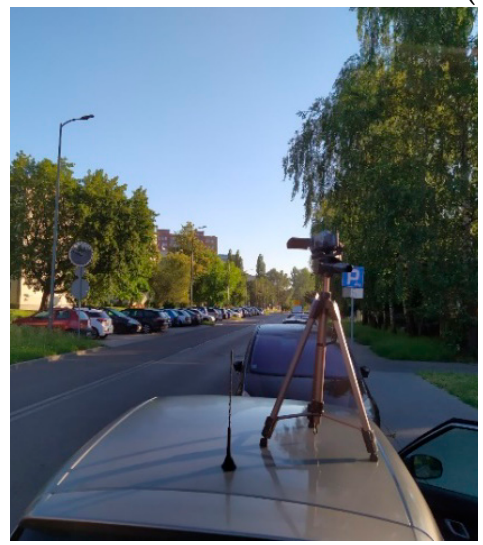

(c)

Figure 3. Location of measurement stations in the three research areas. (a) Research area 1; (b) Research area 2; (c) Research area 3.

Then, the recordings from the cameras were played using the Media Player Classic Home Cinema program, as a result of which it was possible to read the distinguished times of parking maneuvers with an accuracy of milliseconds. Different ways of vehicles entering and exiting the parking spaces were observed during the measurements. Figures 4 and 5 show all the possibilities of behaviors identified during entry to or exit from the parking space.

(a)

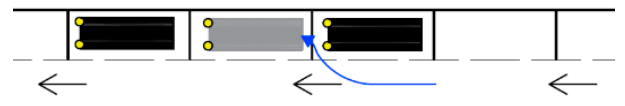

(c)

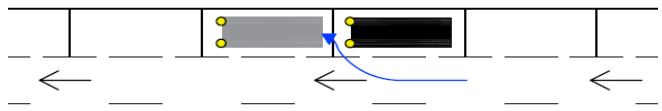

(e)

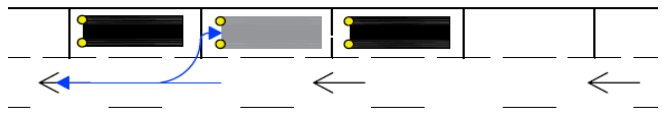

Figure 4. Cont. (b)

(d)
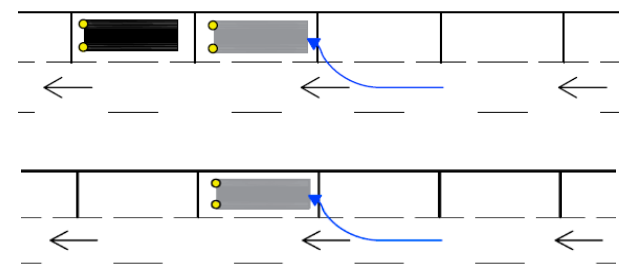

(f)

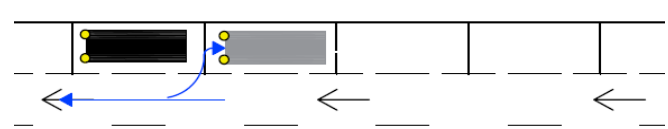


(g)

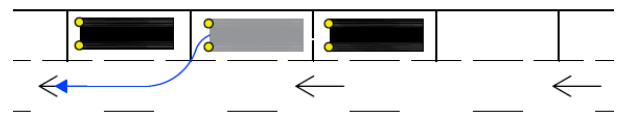

(i)

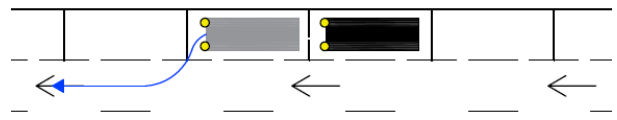

(h)

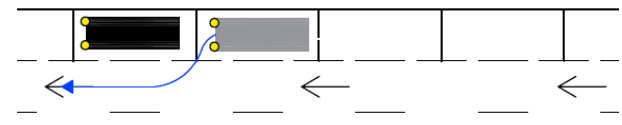

(j)

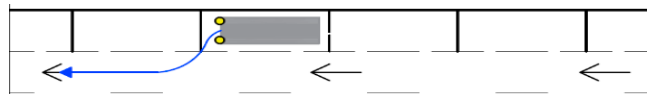

Figure 4. The behavior when drivers' entered or exited the parallel parking space in the case of: (a) a front entry between two parked vehicles; (b) front entry behind the parked vehicle; (c) front entry in front of the parked vehicle; (d) front entry without parked vehicles on the sides; (e) rear entry between two parked vehicles; (f) rear entry behind the parked vehicle; (g) front exit between two parked vehicles; (h) front exit behind the parked vehicle; (i) front exit in front of the parked vehicle; (j) front exit without parked vehicles on the sides.

(a)

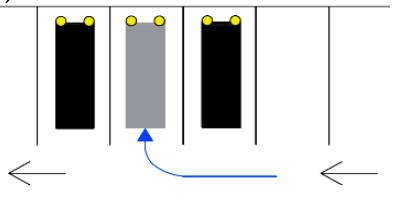

(e)

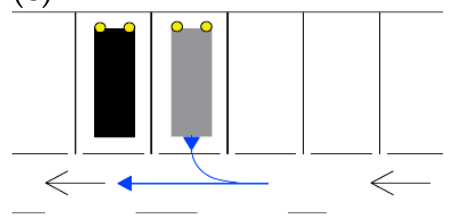

(i)

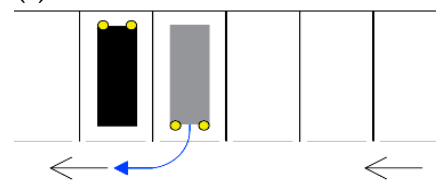

(m)

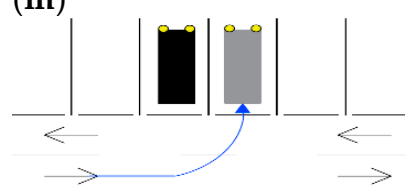

(q)

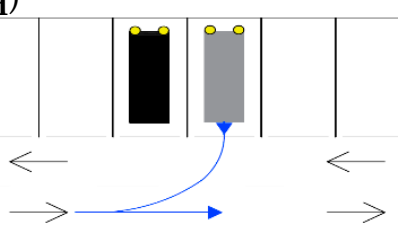

(b)

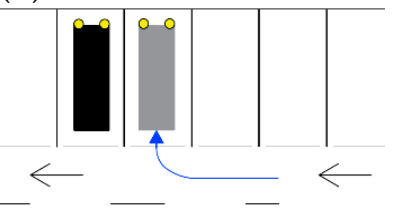

(f)

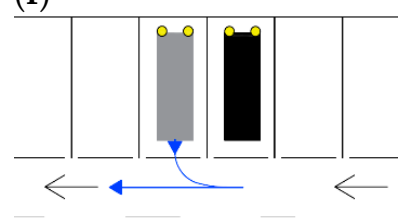

(j)

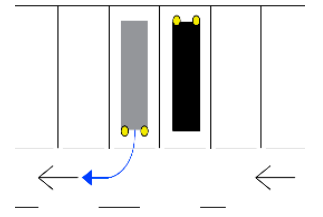

(n)

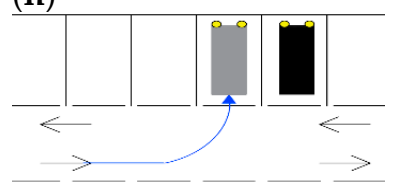

(r)

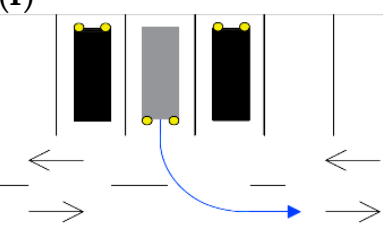

(c)

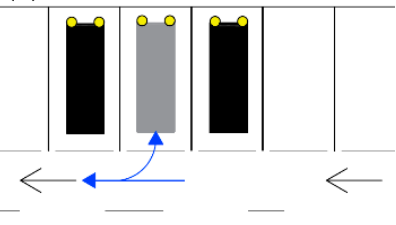

(g)

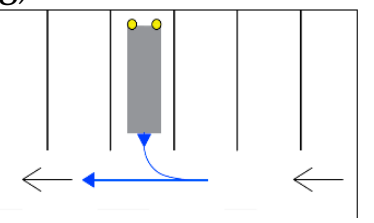

(k)

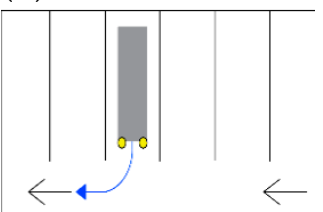

(o)

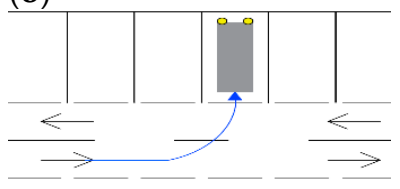

(d)

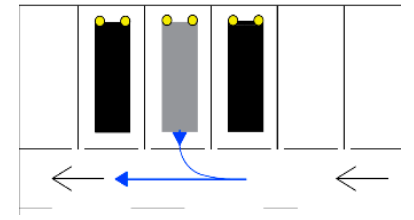

(h)

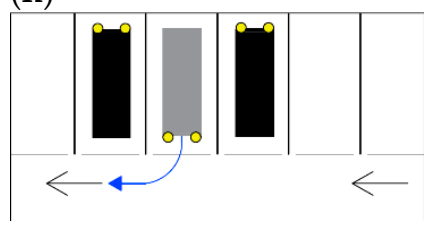

(1)

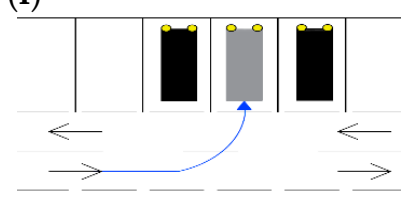

(p)

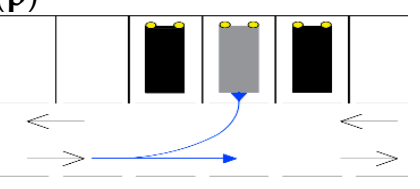

Figure 5. The behavior of drivers entering or exiting the perpendicular parking space in the case of (a) front entry between two parked vehicles from the lane next to the parking space; (b) front entry on the right side of the parked vehicle from the lane next to the parking space; (c) rear entry between two parked vehicles from the lane next to the parking space; (d) rear exit between two parked vehicles to the lane next to the parking space; (e) rear exit on the right side of the parked vehicle to the lane next 
to the parking space; (f) rear exit on the left side of the parked vehicle to the lane next to the parking space; (g) rear exit without parked vehicles on the sides to the lane next to the parking space; (h) front exit from between two parked vehicles to the lane next to the parking space; (i) front exit from the right side of the parked vehicle to the lane next to the parking space; (j) front exit from the left side of the parked vehicle to the lane next to the parking space; (k) front exit without parked vehicles on the sides to the lane next to the parking space; (1) a front entry between two parked vehicles from the lane in the opposite direction; (m) front entry on the right side of the parked vehicle from the lane in the opposite direction; (n) front entry from the left side of the parked vehicle from the lane in the opposite direction; (o) front entry without parked vehicles on the sides from the lane in the opposite direction; (p) rear exit between two parked vehicles to the lane in the opposite direction; (q) rear exit on the right side of the parked vehicle to the lane in the opposite direction; (r) front exit between two parked vehicle to the lane in opposite direction.

Figure 4 shows the behavior observed when drivers entered or exited the parallel parking space (research area 1 and research area 3). Most drivers opted for front entry into the parking space, regardless of the degree of occupancy of parking spaces located at the front and rear to the analyzed parking space. The most common situation when vehicles entered the parking space, in the case of both research areas, was the parking space at the front and a vacant parking space at the rear (Figure $4 \mathrm{~b}$ ). In the case of both research areas, the most frequent situation when drivers exited the parking space was the presence of an occupied parking space at the front, and a vacant parking space at the rear (Figure $4 \mathrm{i}$ ).

Figure 5 shows the behaviors observed during drivers' entry to and exit from the perpendicular parking space (research area 2). Most often, drivers entered the parking space from the lane in the opposite direction (Figure 51-o). Most drivers exited the parking space into the lane next to the parking space. The choice of the lane that the driver planned to go in depended on the direction of his journey. Therefore, if more drivers entered the parking space from the lane in the opposite direction, these drivers would exit the parking space into the lane next to the parking space.

The parking maneuver consists of entry to and exit from the parking space. The total time that the vehicle takes to enter the parking space is the sum of the times of the particular stages from the moment the driver slows down to find a vacant parking space, until the car is in the parking space and does not move. For the article, it was assumed:

$$
t_{t, \text { in }}=t_{1, \text { in }}+t_{2, \text { in }}+t_{3, \text { in }}[\mathrm{s}]
$$

where:

$t_{t, i n}$ - the total time of blocking the traffic flow in the lane from which the vehicle enters the parking space;

$t_{1, i n}$ - the time from the moment the vehicle slows down to find a vacant parking space until the vehicle wheels are turned to the parking space. The moment of deceleration of the vehicle was assumed as the illumination of the vehicle's stop lights in the case when it was already in the parking zone, or in the case when the stop lights are on in front of the parking zone, the moment when the first element of the car crossed the line marking the beginning of the parking zone;

$t_{2, i n}$ - the time from the moment the vehicle wheels are turned to the parking space until the last wheel of the vehicle crossed the line separating the lane and the parking space in the case of the parallel parking space; or the time from the moment the vehicle wheels are turned to the parking space until the last element of the car (front or rear) crossed the line separating the lane and the parking space in the case of the perpendicular parking space;

$t_{3, i n}$ - the time from the moment when the last wheel of the vehicle crossed the separating the lane and the parking space to the moment when the vehicle no longer makes any movement in the case of the parallel parking space; or the time from the moment when the last element of the car (front or rear) crossed the line separating the lane and 
parking space to the moment when the vehicle no longer makes any movement in the case of the perpendicular parking space.

The total time when the vehicle exits from the parking space is the sum of the times of particular stages from the moment when the vehicle signaled its willingness to join the traffic (switching on the turn signal, switching on the reverse lights, or the vehicle movement at the parking space) to the moment when the wheels of the vehicle have the correct track. This time was described by a formula:

$$
t_{t, \text { out }}=t_{1, \mathrm{out}}+t_{2, \mathrm{out}}+t_{3, \mathrm{out}}[\mathrm{s}]
$$

where:

$t_{t, \text { out }}$ - the total time of blocking the flow in the lane on which vehicle exits from the parking space;

$t_{1, \text { out }}$ - the time from the moment when the vehicle signaled its willingness to exit from the parking space (switching on the turn signal, switching on the reverse lights, or the vehicle movement at the parking space) to the moment when the first wheel crossed the line separating the lane and the parking space in the case of the parallel parking space; or the time from the moment when the vehicle was signaled its willingness to exit from the parking space (switching on the turn signal, switching on the reverse lights or the vehicle moving on the parking space) to the moment when the first element of the car (front or rear) crossed the line separating the lane and parking space in the case of a perpendicular parking space;

$t_{2, o u t}$ - the time from the moment the first wheel crossed the line separating the lane and the parking space to the moment the last wheel entered the lane in the case of a parallel parking space; or the time from the moment when the first element of the car (front or rear) crossed the line separating the lane and the parking space to the moment when the last element of the car (front or rear) crossed the line separating the lane and the parking space to the moment the last wheel entered the lane in the case of a perpendicular parking space;

$t_{3, \text { out }}$ - the time from the moment the last wheel enters the lane to the moment when the vehicle wheels had the appropriate track in the case of a parallel parking space; or the time from the moment when the last element of the car (front or rear) crossed the line separating the lane and the parking space to the moment when the wheels of the vehicle had an appropriate track in the case of the perpendicular parking space.

Figure 6 shows, schematically, the times described above in the form of travel stages related to the parking maneuver for the case of parallel parking. The same stages apply to perpendicular parking.

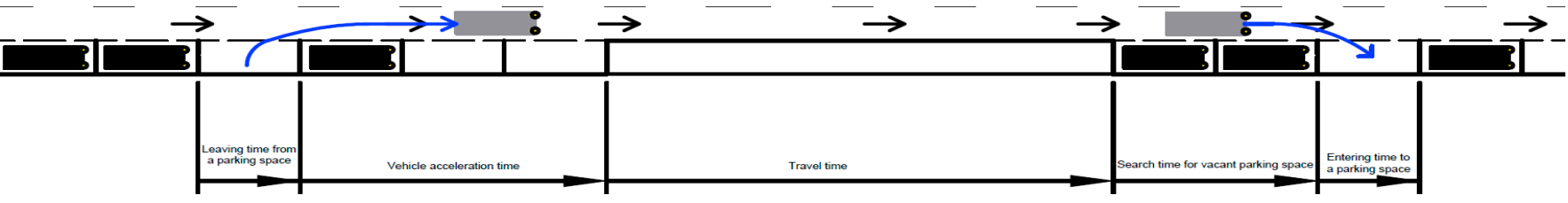

Figure 6. Travel stages related to the parking maneuver.

The mean values and standard deviations for the time of entry to $\left(t_{1, \text { in }}+t_{2, \text { in }}\right)$ and exit from $\left(t_{2, \text { out }}+t_{3, \text { out }}\right)$ the parking space were calculated based on field measurements. Then, it was checked whether there were statistically significant differences between the time of entry to and exit from the parking space between the research areas. For this purpose, the Wilcoxon test was performed. Then, the Shapiro-Wilk test was carried out to check whether the times of entry to and exit from the parking space in the research areas had a normal distribution. In addition, histograms were prepared for these values. Subsequently, the dependence of the time of entry to and exit from the parking space on the use of the 
parking space was analyzed. Moreover, the mean values and standard deviation for the waiting time for the acceptable distance between vehicles moving on the road into which the vehicle exited the parking space $\left(t_{3, \text { out }}\right)$ were calculated. In the next part, two models of the impact of parking on the value of the capacity of the inlet of the intersection with traffic lights were compared for the data obtained from the measurements in research areas in Poland. These were the models presented in HCM 2010 and by S. Wijayaratna for Australian conditions.

\section{Impact of the Parking Maneuver on the Capacity of the Inlets of Intersections with Traffic Lights for Road Traffic Conditions in Poland}

\subsection{Analysis of the Time of Entry to and Exit from the Parking Space}

In this section, the results of the research on the time of entry to (based on time $t_{1, \text { in }}+t_{2, \text { in }}$ ) and exit from (based on time $t_{2, \text { out }}+t_{3, \text { out }}$ ) the parking spaces are presented. Table 3 shows the average maneuver time and the standard deviation for all research areas.

Table 3. Mean time and standard deviation of the particular type of parking maneuver in the research areas $t_{1, \text { in }}+t_{2, \text { in }}$.

\begin{tabular}{|c|c|c|}
\hline Type of Parking Maneuver & Mean Time [s] & Standard Deviation [s] \\
\hline \multicolumn{3}{|c|}{ Research area 1} \\
\hline Front entry & 3.86 & 1.17 \\
\hline Rear entry & 21.53 & 7.30 \\
\hline Front exit & 3.97 & 1.37 \\
\hline \multicolumn{3}{|c|}{ Research area 2} \\
\hline Front entry from the lane next to the parking space & 7.22 & 3.95 \\
\hline Front entry from the lane in the opposite direction & 10.81 & 5.99 \\
\hline Rear entry from the lane next to the parking space & 15.823 & - \\
\hline Rear exit to the lane next to the parking space & 9.77 & 3.02 \\
\hline Rear exit to the lane in the opposite direction & 12.17 & 4.59 \\
\hline Front exit to the lane in the opposite direction & 7.35 & 2.28 \\
\hline \multicolumn{3}{|c|}{ Research area 3} \\
\hline Front entry & 5.16 & 1.95 \\
\hline Rear entry & 8.24 & - \\
\hline Front exit & 3.54 & 0.82 \\
\hline
\end{tabular}

The values for the exit time from the parking space in research areas 1 and 3 are similar: on average, they differ by $0.43 \mathrm{~s}$. Research area 1 had the smallest average entry time to the parking space, whereas the largest was in research area 2 . The front entry time to the parking space between research areas 1 and 3 varied by an average of $1.3 \mathrm{~s}$. The research areas differed regarding the number of lanes next to the parking spaces and the surface of the parking spaces. This difference indicates that the number of lanes or the type of parking spaces affects the entry time to the parking space. The entry times to the parking space in area 2 differed, on average, from areas 1 and 3 depending on the method of performing the maneuver:

- front entry to the parking space from the lane next to the parking space in research area 2 was longer on average by approximately $3.4 \mathrm{~s}$ than the front entry to the parking space in research area 1 , and by approximately $2.1 \mathrm{~s}$ than research area 3;

- front entry to the parking space from the opposite lane to the parking space in research area 2 was longer on average by approximately $7 \mathrm{~s}$ than front entry to the parking space in research area 1 , and by approximately $5.7 \mathrm{~s}$ than research area 3.

A small number of observations of the vehicles rear entry to the parking space in all areas does not allow for a comparison of these times.

The Wilcoxon test was carried out to check whether differences in the time of entry to and exit from the parking space in the research areas were statistically significant. The Wilcoxon test is a nonparametric two-sample comparison test that is often used in traf- 
fic engineering research $[50,51]$. First, the absolute difference is calculated between the paired values. Then, all results are ordered in ascending order (the so-called ranking), which are assigned ranks. In the next step, the ranks are summed separately for negative and positive differences. The smaller value that corresponds to the Wilcoxon test statistic is selected [52,53]. On this basis, the null hypothesis and an alternative hypothesis were formulated:

Hypothesis 1 (H1). the time of entry to or exit from the parking space depends on the characteristics of the research area.

Hypothesis 2 (H2). the time of entry to or exit from the parking space does not depend on the characteristics of the research area.

Tables 4 and 5 present the results of the Wilcoxon test for the time of entry to and exit from the parking space. The critical value for the Wilcoxon test $\left(T_{\alpha}\right)$ was read based on the value of $\alpha=0.05$ and the sample size. The null hypothesis was not rejected in the case of comparing the entry time to the parking space between all research areas and the exit time from the parking space between research areas 1 and 2, as well as research areas 2 and 3 . The null hypothesis should be rejected in favor of the alternative hypothesis in the case of comparing the exit time from the parking space between research areas 1 and 3 . The results of the Wilcoxon test confirm previous assumptions about the impact of the positions of the parking space to the road, the number of lanes, and the surface of parking spaces on the time of entry to and exit from the parking space.

Table 4. Results of the Wilcoxon test for the time of entry to the parking space in the analyzed research areas.

\begin{tabular}{cccc}
\hline Statistics & $\begin{array}{c}\text { Research Areas } \\
\mathbf{1} \text { and } \mathbf{2}\end{array}$ & $\begin{array}{c}\text { Research Areas } \\
\mathbf{1} \text { and 3 }\end{array}$ & $\begin{array}{c}\text { Research Areas } \\
\mathbf{2} \text { and 3 }\end{array}$ \\
\hline$T_{\alpha}$ & 47 & 47 & 91 \\
$T$ & 6 & 40 & 24 \\
$p$-value & $0^{*}$ & 0.048 & 0 * \\
\hline$* p$-value $<0.001$. & & &
\end{tabular}

Table 5. Results of the Wilcoxon test for the time of exit from the parking space in the analyzed research areas.

\begin{tabular}{cccc}
\hline Statistics & $\begin{array}{c}\text { Research Areas } \\
\mathbf{1} \text { and } \mathbf{2}\end{array}$ & $\begin{array}{c}\text { Research Areas } \\
\mathbf{1} \text { and } \mathbf{3}\end{array}$ & $\begin{array}{c}\text { Research Areas } \\
\mathbf{2} \text { and } \mathbf{3}\end{array}$ \\
\hline$T_{\alpha}$ & 25 & 25 & 100 \\
$T$ & 1 & 39 & 0 \\
$p$-value & 0.001 & 0.397 & 0 * \\
\hline
\end{tabular}

The next step was to check the distribution of the times of entry to and exit from the parking space. For this purpose, histograms were developed, and the Shapiro-Wilk test was performed. The Shapiro-Wilk test is used to verify the normality of a random variable. The following hypotheses were formulated for the Shapiro-Wilk test:

Hypothesis 3 (H3). The distribution of the examined feature is a normal distribution.

Hypothesis 4 (H4). The distribution of the examined feature is not a normal distribution.

The critical value for the Shapiro-Wilk test was read, based on the value of $\alpha=0.05$ and the sample size. Table 6 shows the results of the Shapiro-Wilk test, and the critical value for each type of performed parking maneuver. 
Table 6. Results of the Shapiro-Wilk test for a particular type of parking maneuver.

\begin{tabular}{|c|c|c|c|}
\hline Type of Parking Maneuver & Shapiro-Wilk Test & Critical Value & $\begin{array}{l}\text { Rejection of the } \\
\text { Hypothesis }\end{array}$ \\
\hline \multicolumn{4}{|l|}{ Research area 1} \\
\hline Front entry & 0.935 & 0.897 & Yes \\
\hline Front exit & 0.899 & 0.892 & Yes \\
\hline \multicolumn{4}{|l|}{ Research area 2} \\
\hline Front entry from the lane next to the parking space & 0.778 & 0.818 & No \\
\hline Front entry from the lane in the opposite direction & 0.869 & 0.887 & No \\
\hline Rear exit to the lane next to the parking space & 0.971 & 0.908 & Yes \\
\hline Rear exit to the lane in the opposite direction & 0.966 & 0.829 & Yes \\
\hline Front exit to the lane in the opposite direction & 0.919 & 0.788 & Yes \\
\hline \multicolumn{4}{|l|}{ Research area 3} \\
\hline Front entry & 0.906 & 0.916 & No \\
\hline Front exit & 0.973 & 0.918 & Yes \\
\hline
\end{tabular}

The hypothesis about the normal distribution of times was rejected in the case of:

- $\quad$ front entry to the parking space for research area 1;

- front exit from the parking space for research area 1;

- rear exit from the parking space to the lane next to the parking space for research area 2;

- $\quad$ rear exit from the parking space to the lane in the opposite direction for research area 2;

- front exit from the parking space to the lane in the opposite direction for research area 2;

- front entry to the parking space for research area 3;

- front exit from the parking space for research area 3 .

Figure 7 presents histograms of the time of entry to and exit from the parking space in research areas. Histograms make it possible to observe the distribution of values according to the number of observations in particular intervals of the examined variable and around which value a given variable is located. In the case of research areas 1 and 3, the exit time from the parking space for most drivers was 2.5 to $4.5 \mathrm{~s}$. In research area 3 , the exit time from the parking space was more varied between drivers than in research areas 1 and 2; the time of the rear exit from the parking space usually ranged from $8 \mathrm{~s}$ to $9 \mathrm{~s}$. The distribution of the time of rear exit from the parking space into the lane in the opposite direction did not receive more observations in intervals than area 2.

During the analysis of the times of entry to and exit from the parking spaces, it was observed that this time depended on the occupancy of the parking spaces to the front and rear of the analyzed parallel parking space, and the left and right sides of the analyzed perpendicular parking space. In research area 1 , when at least one parking space was vacant in the front or rear of the analyzed parking space, the average entry time to the parking space was $0.8 \mathrm{~s}$ shorter, and the standard deviation was lower by $0.34 \mathrm{~s}$ than in the situation where both parking spaces (front and rear of the analyzed) were occupied. Although at least one parking space was vacant in the front or rear of the analyzed parking space, the average exit time from the parking space was shorter by $0.5 \mathrm{~s}$, and the standard deviation was smaller by $1.2 \mathrm{~s}$ than when both parking spaces (front and rear of the analyzed) were occupied. In the case of research area 2 , when at least one parking space was vacant in the left or right side of the analyzed parking space, the mean entry time to the parking space was shorter by $0.3 \mathrm{~s}$ and the standard deviation was lower by $0.17 \mathrm{~s}$ than in the situation where both parking spaces (on the left and right of the analyzed) were occupied. The average exit time from the parking space was shorter by $0.51 \mathrm{~s}$ when at least one parking space was vacant on the left or right side of the analyzed one, and the standard deviation was smaller by $0.5 \mathrm{~s}$ than when both parking spaces (on the left and right of the analyzed) were occupied. In research area 3, there was a small sample size of the times of entry to 
and exit from the parking space, in the case when both parking spaces (front and rear of the analyzed parking space) were occupied. In connection with the above, the dependence of the time of entry to and exit from the parking space on the use of the parking space was checked (Figure 8).

Between the time of entry to or exit from the parking space and the use of the parking space there was no relationship. The value presented of $\mathrm{R}^{2}$ also indicated the lack of dependence of these two values.

When the driver exited the parking space, disruptions in traffic flow did not occur as often as when the driver entered the parking space. The drivers waited for the acceptable distance between vehicles moving on the road into which the vehicle could exit from the parking space. Notably, 36\% of drivers correctly anticipated the acceptable distance between vehicles moving on the road into which the vehicle could exit from the parking space (in research area 1-approximately 35\%, in research area 2-approximately $22 \%$, and in research area 3-approximately 58\%). The number of drivers waiting to join the traffic when exiting the parking space and the length of the waiting time depended on the traffic volume. In the case of research area 1, during the maneuver of exit from the parking space, there was no situation in which a driver who was moving on the road had to slow down or stop. In research area 2, 25\% of the cases were observed in which a vehicle exit from the parking space caused the need to reduce speed, or a vehicle stopped on the road next to the parking spaces. In the research area 3, 4\% of such cases were recorded. Table 7 shows the average time and standard deviation in the situation of waiting, and shows there was sometimes no need to wait for the acceptable distance between vehicles moving on the road into which the vehicle can exit from the parking space. The time $t_{1 \text {,out }}$ when there was no need to wait for the acceptable distance between vehicles moving on the road for the vehicle to exit from the parking space was shorter than in the situation when drivers waited for this distance.

Drivers waiting for the acceptable distance between vehicles moving on the road was more varied than in the case where there was no such necessity. This is indicated by the value of the standard deviation. The longer acceptable distance between vehicles moving on the road into which the vehicle could exit from the parking space was in research area 2; this was due to increased traffic in research area 2 . There was also a long time of exit from the perpendicular parking space, compared with the parallel parking space.

4.2. Comparison of Models of the Impact of Parking Maneuvers on the Value of the Capacity of the Inlets of Intersections with Traffic Lights for Road Traffic Conditions in Poland

This subsection presents a comparative analysis of the models of the impact of the parking maneuvers on the capacity of the inlets of intersections with traffic lights, for data obtained from field measurements in Poland (Figure 9).

For the model presented by S. Wijayaratna [13], a function was determined for the values obtained from the measurements, and those presented by the author. The value of the function presented in HCM 2010 [48] depends only on the number of lanes. Therefore, only the function value was determined for the data from the measurements carried out in research areas. In the case of data from the research areas of entry time to the parking space, the value of the $S$. Wijayaratna function is characterized by a lower decline dynamic than the value of this function for the data presented by the author. The HCM 2010 function, with a smaller number of parking maneuvers, assumes similar values to those of the $S$. Wijayaratna function for data from the research areas. In the case of research areas 1 and 2 , the value of the $S$. Wijayaratna function for the measurement data was similar to the function from HCM 2010. 
(a)

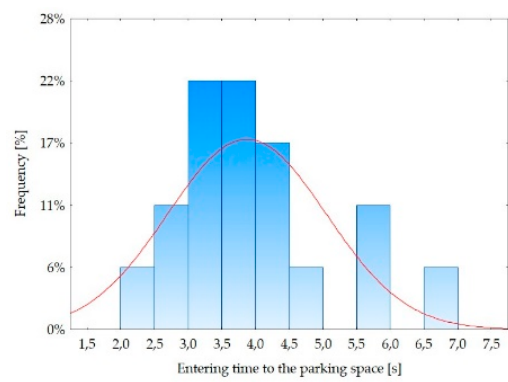

(c)

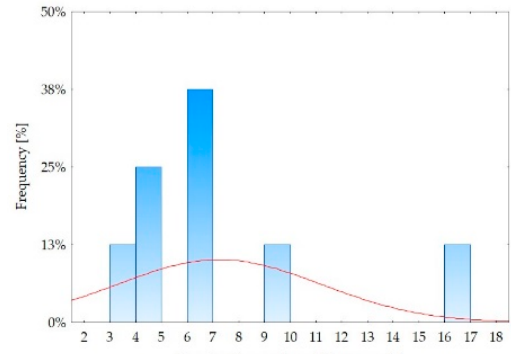

(e)

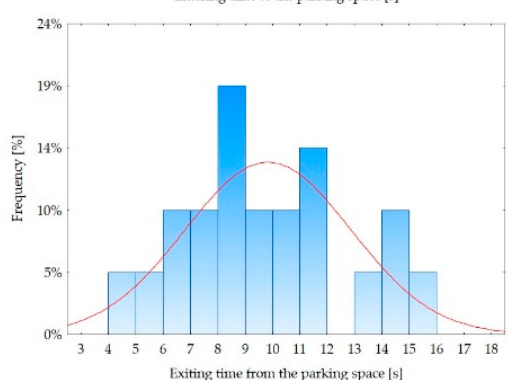

(b)

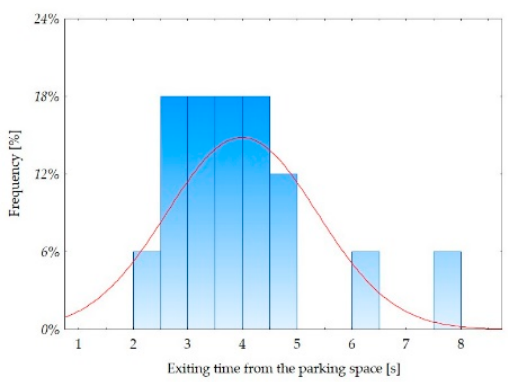

(d)

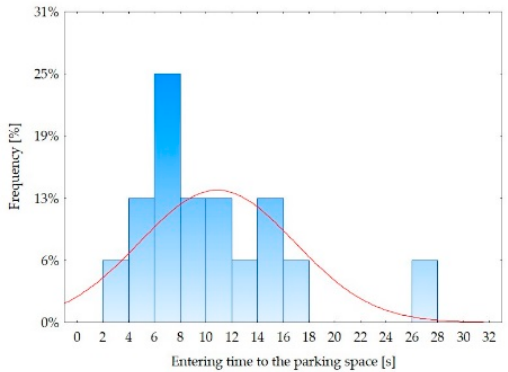

(f)

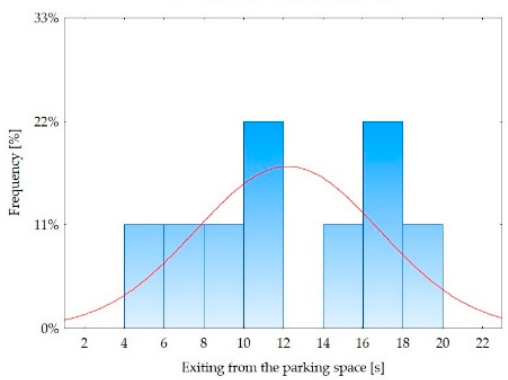

(g)

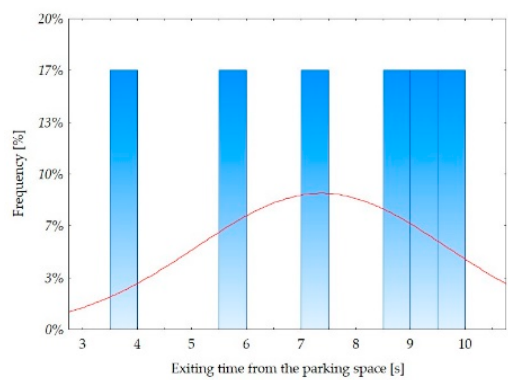

(h)

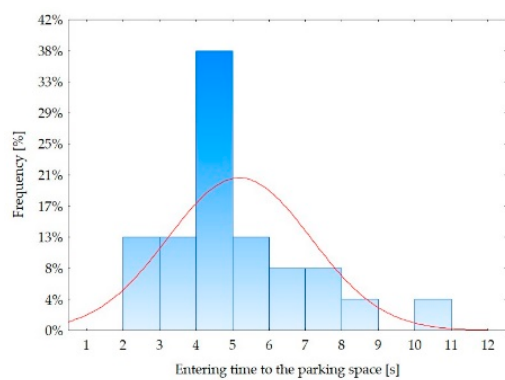

(i)

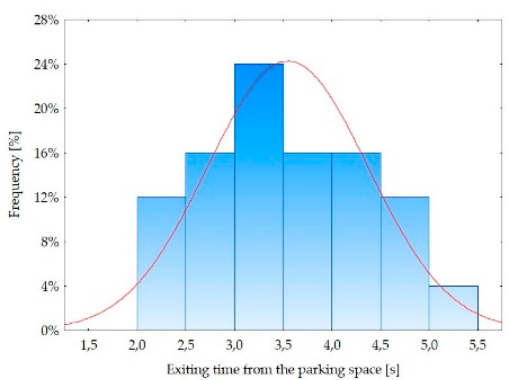

Figure 7. Histograms for the time of: (a) front entry for research area 1; (b) front exit for research area $1 ;$ (c) front entry from the lane next to the parking space for research area $2 ;(\mathbf{d})$ front entry from the lane in the opposite direction for research area 2; (e) rear exit to the lane next to the parking space for research area 2; (f) rear exit to the lane in the opposite direction for research area 2; (g) front exit to the lane next to the parking space for research area 2 ; (h) front entry into area 3 ; (i) front exit for research area 3. 
(a)

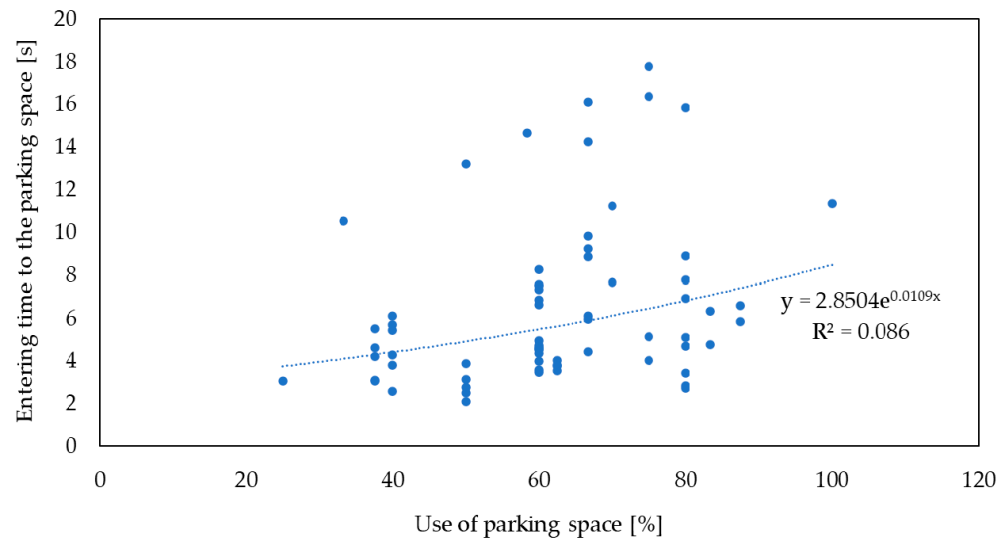

(b)

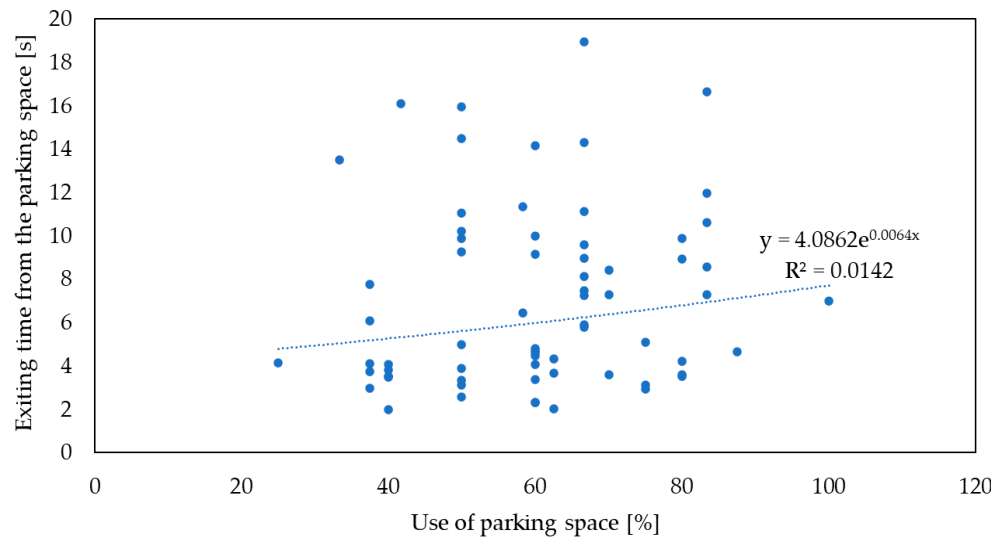

Figure 8. Time of (a) entry to the parking space; (b) exit from the parking space, dependent from the use of the parking space in the analyzed research areas.

Table 7. Mean time and standard deviation in the situations where the vehicle is waiting or not having to wait for the acceptable distance between vehicles moving on the road, into which the vehicle can exit from the parking space.

\begin{tabular}{|c|c|c|}
\hline The Situation When Exiting the Parking Space & Mean Time $[s]$ & Standard Deviation $[\mathrm{s}]$ \\
\hline \multicolumn{3}{|c|}{ Research area 1} \\
\hline Waiting for a gap between vehicles & 9.57 & 7.89 \\
\hline No waiting for a gap between vehicles & 3.45 & 2.33 \\
\hline \multicolumn{3}{|c|}{ Research area 2} \\
\hline $\begin{array}{l}\text { Waiting for the gap between the vehicles when rear exiting } \\
\text { to the lane next to the parking space }\end{array}$ & 12.91 & 8.67 \\
\hline $\begin{array}{l}\text { Waiting for the distance between the vehicles when front } \\
\text { exiting to the lane next to the parking space }\end{array}$ & 14.958 & - \\
\hline $\begin{array}{l}\text { Waiting for the distance between the vehicles when rear } \\
\text { exiting to the lane in the opposite direction }\end{array}$ & 6.71 & 4.84 \\
\hline $\begin{array}{l}\text { No waiting for the distance between the vehicles when rear } \\
\text { exiting to the lane next to the parking space }\end{array}$ & 2.47 & 1.17 \\
\hline $\begin{array}{l}\text { No waiting for the distance between the vehicles while front } \\
\text { exiting to the lane next to the parking space }\end{array}$ & 2.66 & 1.18 \\
\hline $\begin{array}{l}\text { No waiting for the distance between the vehicles while front } \\
\text { exiting to the lane in the opposite direction }\end{array}$ & 2.49 & - \\
\hline \multicolumn{3}{|c|}{ Research area 3} \\
\hline Waiting for a gap between vehicles & 11.35 & 8.79 \\
\hline No waiting for a gap between vehicles & 2.86 & 2.49 \\
\hline
\end{tabular}


Vehicles exiting the parking space in most of the analyzed cases did not disturb the road traffic. Therefore, the time of entry to the parking space was taken into account to determine the maximum possible number of parking maneuvers for the analyzed models. In research area 1 there were two lanes for parking spaces, which, according to HCM 2010, results in the maximum number of 380 possible parking maneuvers per hour. In research areas 2 and 3, there was one lane at the parking spaces; therefore, the maximum number of parking maneuvers was 180 . For the value of entry time to the parking spaces presented in [13], in one hour, it is possible to perform a maximum of 138 parking maneuvers. The determined average time of the front entry to the parking space in research area 1 allowed the performance of 932 parking maneuvers per hour. In research area 2, the value was 374 parking maneuvers per hour, and in research area 3 the value was 697 parking maneuvers per hour.

(a)

0

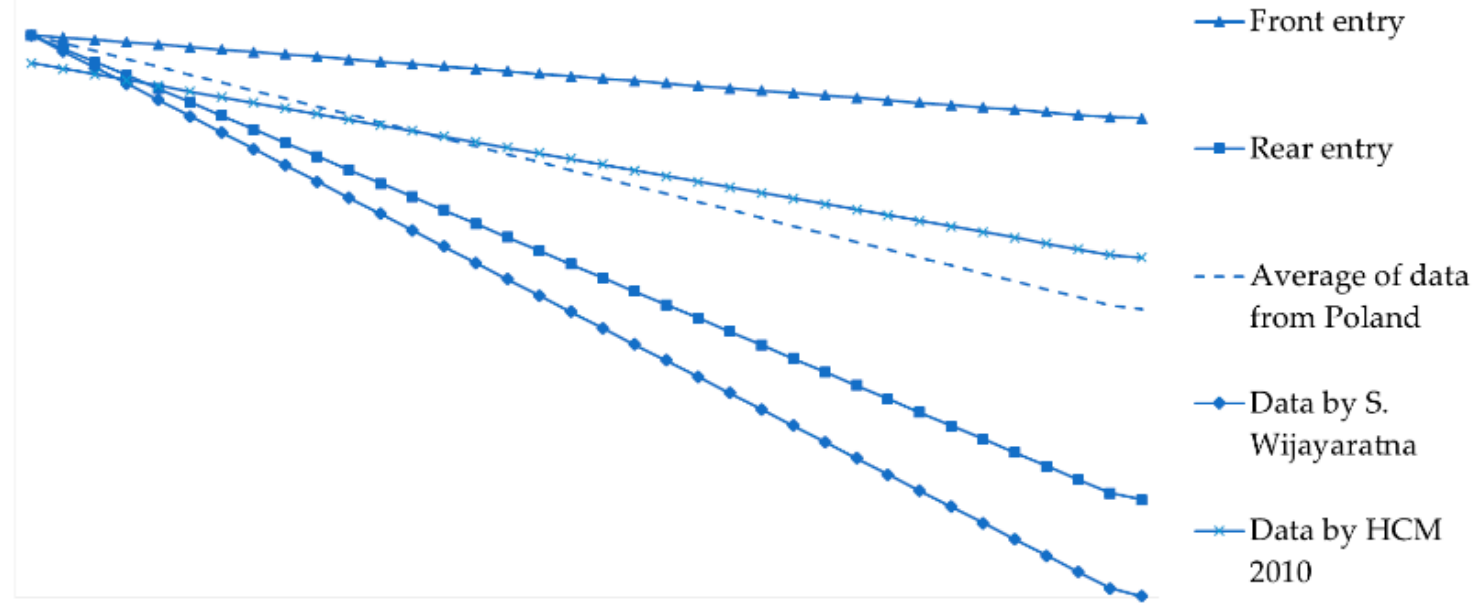

$\begin{array}{llllllllllllllllll}0 & 8 & 16 & 24 & 32 & 40 & 48 & 56 & 64 & 72 & 80 & 88 & 96 & 104 & 112 & 120 & 128 & 136\end{array}$ $\mathrm{Nm}$ [veh./h]

(b)

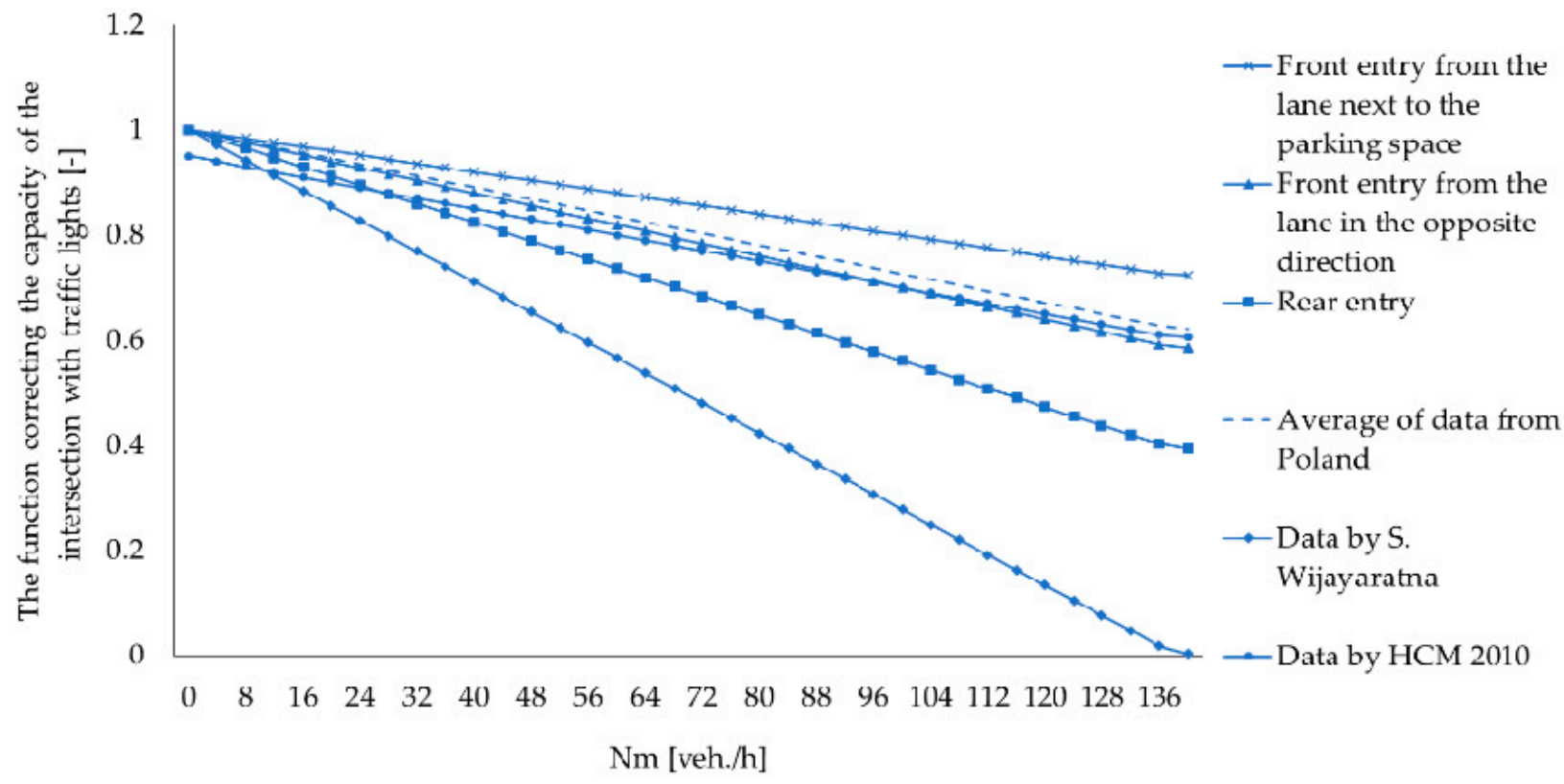

Figure 9. Cont. 
(c)

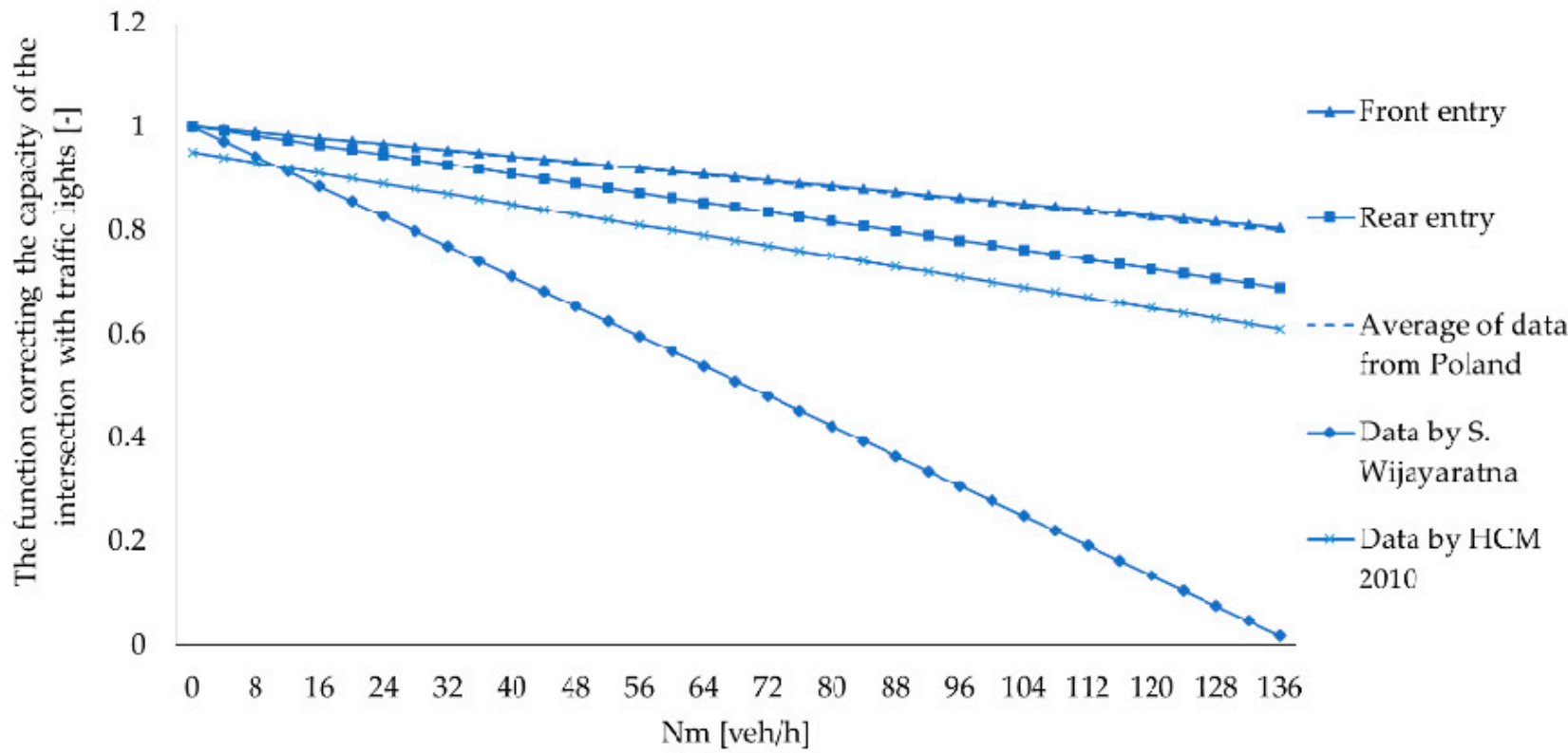

Figure 9. Comparison of the models of the impact of parking maneuvers on the value of the capacity of the inlet of intersections with traffic lights under Polish conditions for (a) research area 1; (b) research area $2 ;(\mathbf{c})$ research area 3.

\section{Discussion}

The literature review presented in the second chapter indicates that studies on the impact of on-street parking on road traffic are conducted in various countries around the world. Models presented in foreign literature developed based on research conducted in these countries are characterized by various independent variables. Differences in the use of factors are due to varied behavior during the parking maneuver in the countries where the research was conducted. To the knowledge of the authors of the article, no research has been carried out on the impact of parking maneuvers on the capacity of the inlets of intersections with traffic lights in Poland so far.

Measurements were carried out in areas that differed in terms of geometry, i.e., positions of the parking space to the road, the number of lanes, and the type of parking space surface. Different behaviors were observed when drivers entered or exited the parking space. The largest number of front entries to the parking space was observed in all research areas. Front exits from the parking space were the only possible maneuver in research areas 1 and 3 , whereas in research area 2 the most rear exits from the parking space were observed. A further discussion was presented for these cases of parking maneuvers.

In research area 1, there were parallel parking spaces, the surface of which was the same as the road, and there were two lanes next to the parking spaces. The average entry time to the parking space was $3.86 \mathrm{~s}$. The average exit time from the parking space was $3.97 \mathrm{~s}$. In research area 2, there were perpendicular parking spaces, the surface of which was slightly elevated above the road, and there was one lane next to the parking spaces. The average entry time to the parking space in research area 2 was $9.61 \mathrm{~s}$, and the average exit time from the parking space was $10.17 \mathrm{~s}$. In research area 3, there were parallel parking spaces, the surface of which was slightly elevated above the road, and there was a lane next to the parking spaces. The average entry time to the parking space was $5.16 \mathrm{~s}$ and the average exit time from the parking space was $3.54 \mathrm{~s}$.

The differences in the entry time to the parking spaces in the research areas were determined as statistically significant based on the Wilcoxon test results. In the case of the exit time from the parking space, the differences between the values obtained from field measurements were statistically significant between research area 2 and research areas 1 and 3. Differences in geometric solutions in the research areas contributed to the duration of exit from the parking space. The lack of differences in the exit time from the parking 
space between areas 1 and 3 indicated that the number of lanes next to the parking spaces and the type of surface of parking spaces did not affect the exit time from the parking space. However, the number of lanes affected the traffic flow conditions of the lane next to the parking spaces. Drivers moving on the lane next to the parking area could change the lane to allow the driver to exit from the parking space.

The results of the time taken to enter or exit the parking space differ in the literature from those obtained from the measurements carried out in research areas in Poland. The average time of entry to and exit from the parallel parking space was examined in the work of [44]. The authors distinguished the times depending on the parking spaces occupied before and after the analyzed one, and the time of the day. At noon, the average time of entry to and exit from the parking space, for when both parking spaces were occupied was $13.40 \mathrm{~s}$ and $10.44 \mathrm{~s}$, respectively. If one parking space in front was occupied $-5.61 \mathrm{~s}$ and $6.74 \mathrm{~s}$, respectively. If the rear was occupied-7.13 s and $4.75 \mathrm{~s}$, respectively. In the case where both parking spaces were vacant, this time was $4.32 \mathrm{~s}$ and $3.96 \mathrm{~s}$. In the afternoon, the average time of entry to and exit from the parking space, if both parking spaces were occupied, was $10.72 \mathrm{~s}$ and $9.30 \mathrm{~s}$, respectively. If one parking space in front was occupied$6.50 \mathrm{~s}$ and $6.61 \mathrm{~s}$; if the space in the rear was occupied-7.80 s and $4.39 \mathrm{~s}$; if both parking spaces were vacant, this time was $4.51 \mathrm{~s}$ and $3.80 \mathrm{~s}$, respectively. The work [45] presents the results of research on the time of entry to and exit from parallel and perpendicular parking spaces. The average values of the entry time to the parallel parking space, similarly to the previously discussed work, were presented depending on the occupancy of the parking spaces to the front and rear of the analyzed one. The average time of front entry to the parking space, when both places were occupied, was $7.7 \mathrm{~s}$; rear entry-21.2 s; in the case when only the front parking space was occupied-3.4 s; if the rear was occupied-4.2 s. The exit time from the parking space to the lane next to the parking space was $6.3 \mathrm{~s}$, while for the lane to the opposite direction this was $5.5 \mathrm{~s}$. The entry time to the perpendicular parking space was tested for the case of a vehicle moving from the lane next to the parking spaces, and the lane from the opposite direction. This time was $4.9 \mathrm{~s}$ in both cases. The exit time from the parking space was also tested for the case of exiting into the lane next to the parking space, and the lane in the opposite direction. In the first case, this was $9.6 \mathrm{~s}$, while the second was $11.8 \mathrm{~s}$. The results of the pilot study carried out in Poland, and the comparison of the results with the values of the time of entry to and exit from the parking space presented in the literature, confirm the need to conduct more studies to determine the impact of on-street parking on road traffic parameters in Poland.

As presented in the previous paragraph, the occupancy (none, one, or both parking spaces at the front/left/rear/right) of parking spaces located directly next to the analyzed parking spaces affects the time of entry to and exit from a parking space. The occupancy of parking spaces located directly next to the analyzed one affects the time of entry to and exit from the parking space based on the results of the research carried out in this article. Between the time of entry to or exit from the parking space, and the use of the parking space, there is no relationship based on the value of $R^{2}$. This finding indicates that more factors determine the time of entry to and exit from the parking space. Therefore, it is common to continue to investigate the time of entry to and exit from the parking space to determine the factors that determine its duration under Polish conditions.

Drivers who exit from the parking space wait for the acceptable distance between the vehicles in the traffic flow to which the driver joins, to avoid causing disturbances in road traffic. In the case of the research areas, $36 \%$ of drivers waited for the acceptable distance between vehicles moving on the road into which the vehicle exits from the parking space. In research area 1, the drivers in the studied period did not cause any disruptions in traffic flow when their vehicle exited the parking space, and in the research area 3 there were only $4 \%$ of such cases. In the research area $2,25 \%$ of drivers exiting their parking space caused disruptions to the traffic flow of which they were joining. A driver exiting from a perpendicular parking space is more likely to disrupt the traffic flow than a parallel parking space, due to poor visibility. Drivers exiting from a parallel parking space did not cause 
disturbances in the traffic flow. In the case of a perpendicular parking space, the function to correct the exit time from the parking space should be introduced, because this maneuver did not cause interference in all cases.

In the next part of the article, the models of the impact of on-street parking on the capacity of the intersection with traffic lights presented in the literature (correction functions) were compared. Data obtained from measurements carried out in research areas in Poland were used as variables in the models analyzed. The maximum number of maneuvers to entry to the parking space, determined from measurements in Poland, was greater than those presented by S. Wijayaratna for Australian conditions [13]. In addition, the shapes of the presented functions differed from each other, which confirms the previous assumptions about the need to develop appropriate models of the impact of on-street parking on the value of the capacity of the intersection with traffic lights for road traffic conditions in Poland.

In many cities around the world, the transport infrastructure does not meet the transport needs of residents [53,54]. The lack of space for its expansion causes an imbalance between supply and demand. Traffic engineers are looking for solutions that allow for the efficient movement of people with a minimal impact of transport on the environment in line with sustainable development. The closeness of the on-street parking to travel destinations makes drivers most likely to choose it as a place to leave the vehicle. The maneuver to enter or exit a parking space not only affects traffic delays and the capacity of intersections with traffic lights, but traffic disruptions caused by the parking maneuver have a negative impact on the environment [55]. As there is no possibility to eliminate on-street parking, it necessary to look for solutions that will minimize the negative impact on the environment; thus cities must become compatible with sustainable transport. The results of the research will allow for the design and construction of an optimal parking infrastructure that will meet the needs of road users while minimizing the negative impact on road conditions and the natural environment following sustainable development.

\section{Conclusions}

The article aimed to estimate the influence of parking maneuvers on the capacity of intersections with traffic lights for road traffic conditions in Poland. This estimation was made by comparing the value of the functions correcting the capacity of intersections with traffic lights on the conditions of on-street parking developed in foreign countries based on data from empirical measurements carried out in Poland. Furthermore, the impact of the time taken to enter and exit a parking space on traffic disruptive areas under Polish conditions was examined. The presented research results indicate that the entry to and exit from a parking space depend on the position of the parking space to the road, the use of the parking space located directly next to the analyzed, the number of lanes, and the surface of the parking space.

The research carried out in the article was a pilot study, which is the basis for its continuation. The limitation of the research presented in the literature was the small number of research areas; the research was carried out in three research areas. These areas were characterized by different positions of the parking space to the road, the number of lanes, and the surface of the parking space. At a later stage of the work, it is planned to collect a larger research sample and, on this basis, develop a model of the impact of on-street parking on the value of the capacity of intersections with traffic lights on road traffic conditions in Poland. Moreover, an attempt will be made to develop a function that characterizes the time of a parking maneuver. This function will allow determining the impact of on-street parking on the selected parameters of road traffic. In the case of a maneuver exit from the parking space, it will be verified whether this maneuver causes a significant disruption of traffic conditions. For this purpose, a function correcting the maneuver of the exit from a parking space will be developed, as was suggested in [13]. 
Author Contributions: Conceptualization, A.K. and E.M.; methodology, A.K. and E.M.; software, A.K. and E.M.; validation, A.K. and E.M.; formal analysis, A.K. and E.M.; investigation, A.K. and E.M.; resources, A.K. and E.M.; data curation, A.K. and E.M.; writing-original draft preparation, A.K. and E.M.; writing-review and editing, A.K. and E.M.; visualization, A.K. and E.M.; supervision, A.K. and E.M. All authors have read and agreed to the published version of the manuscript.

Funding: The research is part of a research project entitled "Analysis of road traffic parameters in the on-street parking functioning conditions". The research is carried out at the Department of Transport Systems, Traffic Engineering and Logistics, Faculty of Transport and Aviation Engineering, Silesian University of Technology.

Institutional Review Board Statement: Not applicable.

Informed Consent Statement: Not applicable.

Data Availability Statement: Not applicable.

Acknowledgments: The authors would like to thank the Reviewers for their profound and valuable comments, which have contributed to enhancing the standard of the paper, as well as the authors' future research in this area.

Conflicts of Interest: The authors declare no conflict of interest.

\section{References}

1. Jacyna, M.; Wasiak, M.; Kłodawski, M.; Gołębiowski, P. Modelling of Bicycle Traffic in the Cities Using VISUM. Procedia Eng. 2017, 187, 435-441. [CrossRef]

2. Dingil, A.E.; Schweizer, J.; Rupi, F.; Stasiskiene, Z. Transport indicator analysis and comparison of 151 urban areas, based on open source data. Eur. Transp. Res. Rev. 2018, 10, 1-9. [CrossRef]

3. Ivan, I.; Horák, J. Demand and supply of transport connections for commuting in the Czech Republic. In Geoinformatics for Intelligent Transportation; Ivan, I., Benenson, I., Jiang, B., Horák, I., Haworth, J., Inspector, T., Eds.; Springer: Cham, Switzerland, 2015; pp. 137-147. [CrossRef]

4. Snowdon, J.; Gkountouna, O.; Züfle, A.; Pfoser, D. Spatiotemporal traffic volume estimation model based on GPS samples. In Proceedings of the Fifth International ACM SIGMOD Workshop on Managing and Mining Enriched Geo-Spatial Data, Houston, TX, USA, 10 June 2018; pp. 1-6. [CrossRef]

5. Pechatnova, E.V.; Kuznetsov, V.N. Study of the relationship between time and traffic flow on motorways. In Journal of Physics: Conference Series; IOP Publishing: Bristol, UK, 2019; Volume 1333, pp. 32-63. [CrossRef]

6. Newman, P. Transport infrastructure and sustainability: A new planning and assessment framework. Smart Sustain. Built Environ. 2015, 4, 140-153. [CrossRef]

7. Dingil, A.E.; Rupi, F.; Stasiskiene, Z. A macroscopic analysis of transport networks: The influence of network design on urban transportation performance. Int. J. Transp. Dev. Integr. 2019, 3, 331-343. [CrossRef]

8. Milazzo, J.S.; Rouphail, N.M.; Hummer, J.E.; Allen, D.P. Effect of Pedestrians on Capacity of Signalized Intersections. Transp. Res. Rec. 1998, 1646, 37-46. [CrossRef]

9. Lai, Y.W.; Shangguan, P.; Rong, J.; Liu, X.M. Influence of pedestrian on capacity of signalized intersection with channelization island. In Proceedings of the ICCTP 2011: Towards Sustainable Transportation Systems, Nanjing, China, 14-17 August 2011; pp. 848-858. [CrossRef]

10. Di, W.; Jing, Z.; Xiaoguang, Y. Impact of bus stop on signalized intersection capacity. In Proceedings of the 2009 Second International Conference on Intelligent Computation Technology and Automation, Massachusetts, WA, USA, 10-11 October 2009; Volume 3, pp. 619-624. [CrossRef]

11. Yao, J.; Zhang, K.; Zhao, J.; Xu, J.; Liu, S. Capacity Study of Signalized Intersection Affected by Bus Station at Upstream. In Proceedings of the 2015 3rd International Conference on Computer and Computing Science (COMCOMS), Hanoi, Vietnam, 22-24 October 2015; pp. 20-23. [CrossRef]

12. Cao, J.; Menendez, M. Generalized effects of on-street parking maneuvers on the performance of nearby signalized intersections. Transp. Res. Rec. 2015, 2483, 30-38. [CrossRef]

13. Wijayaratna, S. Impacts of on-street parking on road capacity. In Proceedings of the Australasian Transport Research Forum, Sydney, Australia, 30 September-2 October 2015.

14. Washburn, S.S.; Cruz-Casas, C.O. Impact of trucks on signalized intersection capacity. Comput. Aided Civ. Infrastruct. Eng. 2010, 25, 452-467. [CrossRef]

15. Kockelman, K.M.; Shabih, R.A. Effect of light-duty trucks on the capacity of signalized intersections. J. Transp. Eng. 2000, 126, 506-512. [CrossRef]

16. Liu, P.; Lu, J.J.; Fan, J.; Pernia, J.C.; Sokolow, G. Effects of U-turns on capacities of signalized intersections. Transp. Res. Rec. 2005, 1920, 74-80. [CrossRef] 
17. Wei, Z.; Zhang, Y.; Guo, X.; Zhang, X. Modeling Capacity of Through Movement at Signalized Intersection Affected by Short Left-Turn Bay under Different Signal Settings. Transp. Res. Rec. 2021, 2675, 1209-1223. [CrossRef]

18. Macioszek, E.; Iwanowicz, D. A back-of-queue model of a signal-controlled intersection approach developed based on analysis of vehicle driver behavior. Energies 2021, 14, 1204. [CrossRef]

19. Tracz, M.; Chodur, J.; Gaca, S.; Gondek, S.; Kieć, M.; Ostrowski, K. Metoda Obliczania Przepustowości Skrzyżowań Z Sygnalizacja świetlna; Generalna Dyrekcja Dróg Krajowych i Autostrad: Warszawa, Poland, 2004.

20. Forschungsgesellschaft für Straßen- und Verkeherswesen. Handbuch für die Bemessung von Straßenverkehrsanlagen; (HBS 2015); Forschungsgesellschaft für Straßen- und Verkehrswesen e. V.: Köln, Germany, 2015.

21. Transportation Association of Canada. Canadian Capacity Guide for Signalized Intersections, 3rd ed.; The Institute of Transportation Engineers: Ottawa, ON, Canada, 2008.

22. Bennett, D. Guide to Traffic Management Part 3: Traffic Studies and Analysis; Austroads: Sydney, Australia, 2020.

23. Transportation Research Board. A Guide for Multimodal Mobility Analysis (HCM 2016). In Highway Capacity Manual, 6th ed.; Transportation Research Board: Washington, WA, USA, 2016.

24. Zong, F.; Yu, P.; Tang, J.; Sun, X. Understanding parking decisions with structural equation modeling. Phys. A Stat. Mech. Its Appl. 2019, 523, 408-417. [CrossRef]

25. Biswas, S.; Chandra, S.; Ghosh, I. Effects of on-street parking in urban context: A critical review. Transp. Dev. Econ. 2017, 3, 10. [CrossRef]

26. Cao, J.; Menendez, M.; Waraich, R. Impacts of the urban parking system on cruising traffic and policy development: The case of Zurich downtown area, Switzerland. Transportation 2019, 46, 883-908. [CrossRef]

27. Duda-Wiertel, U. Search traffic w obszarach z deficytem miejsc postojowych. Transp. Miej. I Reg. 2021, 3, 19-26.

28. Hainalkar, G.N.; Vanjale, M.S. Smart parking system with pre \& post reservation, billing and traffic app. In Proceedings of the 2017 International Conference on Intelligent Computing and Control Systems (ICICCS), Madurai, India, 15-16 June 2017; pp. 500-505. [CrossRef]

29. Kurek, A.; Macioszek, E. Analysis of the Variability of Parking Characteristics in A Weekly Distribution in the Conditions of PPZ and DPI Functioning. In Proceedings of the 6th International Conference on Civil Structural and Transportation Engineering (ICCSTE'21), Virtual Conference, 17-19 May 2021. [CrossRef]

30. Ortega, J.; Moslem, S.; Palaguachi, J.; Ortega, M.; Campisi, T.; Torrisi, V. An Integrated Multi Criteria Decision Making Model for Evaluating Park-and-Ride Facility Location Issue: A Case Study for Cuenca City in Ecuador. Sustainability 2021, 13, 7461. [CrossRef]

31. Kitthamkesorn, S.; Chen, A.; Opasanon, S.; Jaita, S. A P-Hub location problem for determining Park-and-Ride facility with the weibit-based choice model. Sustainability 2021, 13, 7928. [CrossRef]

32. Macioszek, E.; Kurek, A. P\&R parking and bike-sharing system as solutions supporting transport accessibility of the city. Transp. Probl. 2020, 15, 275-286. [CrossRef]

33. Macioszek, E.; Kurek, A. The use of a park and ride system a case study based on the City of Cracow (Poland). Energies 2020, 13, 3473. [CrossRef]

34. Macioszek, E.; Kurek, A. The analysis of the factors determining the choice of park and ride facility using a multinomial logit model. Energies 2021, 14, 203. [CrossRef]

35. Portilla, A.I.; Oreña, B.A.; Berodia, J.L.; Díaz, F.J. Using M/M/ $\infty$ Queueing Model in On-Street Parking Maneuvers. J. Transp. Eng. 2009, 135, 527-535. [CrossRef]

36. Gao, J.; Ozbay, K. Modeling double parking impacts on urban street. In Proceedings of the Transportation Research Board 95th Annual Meeting, Washington, WA, USA, 14-16 January 2016; Volume 12, pp. 1-15.

37. Guo, H.; Gao, Z.; Yang, X.; Zhao, X.; Wang, W. Modeling travel time under the influence of on-street parking. J. Transp. Eng. 2012, 138, 229-235. [CrossRef]

38. Mei, Z.; Chen, J. Modified motor vehicles travel speed models on the basis of curb parking setting under mixed traffic flow. Math. Probl. Eng. 2012, 2012, 1-14. [CrossRef]

39. Sa, S.; George, S.; Ashalatha, R. Effect of Side frictions on Traffic Characteristics of urban arterials. Transp. Res. Procedia 2016, 17, 636-643. [CrossRef]

40. Patkar, M.; Dhamaniya, A. Effect of on-street parking on effective carriageway width and capacity of urban arterial roads in India. European Transport. Eur. Transp. 2019, 73, 1-17.

41. Cao, Y.; Yang, Z.Z.; Zuo, Z.Y. The effect of curb parking on road capacity and traffic safety. Eur. Transp. Res. Rev. 2017, 9, 4. [CrossRef]

42. He, Y.; Li, J. Study on the Influence Coefficient of Road Capacity Caused by Vehicles Pulling in and out of Parking Spaces for Roadside Parking. In Proceedings of the ICCTP 2011: Towards Sustainable Transportation Systems, Nanjing, China, 14-17 August 2011; pp. 1148-1156. [CrossRef]

43. Algburi, T.F.S.; Özen, H.; Kaykioğlu, G.; Güneş, E.; Güneş, Y.; Çelik, S.Ö.; Koçak, A. Characteristics of on-street parking in Istambul. J. Eng. Nat. Sci. 2017, 35, 575-584.

44. Yousif, S. A study into on-street parking: Effects on traffic congestion. Traffic Eng. Control. 1999, 40, 424-427.

45. Yousif, S.; Purnawan, S.Y. Traffic operations at on-street parking facilities. Proc. Inst. Civ. Eng. Transp. 2004, 157, 189-194. [CrossRef] 
46. Yousif, S. Comparison of Accepted Gaps for Different On-Street Parking Designs. 2000. Available online: http:/ / usir.salford.ac. uk/id/eprint/9730/3/Paper_Paris_-_ORIGINAL.pdf (accessed on 10 June 2021).

47. Transportation Research Board. Highway Capacity Manual 2010 (HCM 2010); Transportation Research Board: Washington, WA, USA, 2010.

48. Directorate General of Highways Ministry of Public Works. Indonesian Highway Capacity Manual; Directorate General of Highways Ministry of Public Works: Jakarta, Indonesia, 1995.

49. Macioszek, E. Analysis of significance of differences between psychotechnical parameters for drivers at the entries to one-lane and turbo roundabouts in Poland. In Intelligent Transport Systems and Travel Behaviour; Advances in Intelligent Systems and Computing; Sierpiński, G., Ed.; Springer International Publishing: Cham, Switzerland, 2017; Volume 505, pp. 149-161. [CrossRef]

50. Kurek, A.; Macioszek, E. Daily variability of the use of parking spaces in the Paid Parking Zone covered by Dynamic Parking Information before and during the covid-19 pandemic. Sci. J. Sil. Univ. Technol. Ser. Transp. 2022, 114, 55-65. [CrossRef]

51. Woolson, R.F. Wilcoxon signed-rank test. Wiley Encycl. Clin. Trials 2007, 1-3. [CrossRef]

52. Cuzick, J. A Wilcoxon-type test for trend. Stat. Med. 1985, 4, 87-90. [CrossRef] [PubMed]

53. Wang, L.; Xue, X.; Zhao, Z.; Wang, Z. The impacts of transportation infrastructure on sustainable development: Emerging trends and challenges. Int. J. Environ. Res. Public Health 2018, 15, 1172. [CrossRef] [PubMed]

54. Bryce, J.M. Developing sustainable transportation infrastructure. In American Standards and Testing Materials (ASTM); International Standards Worlwide: West Conshohocken, PA, USA, 2008.

55. Sisiopiku, V.P. On-street parking on state roads. In Proceedings of the ITE Annual Meeting Compendium, Washington, WA, USA, 19-22 August 2001. 